OPEN ACCESS

Edited by:

Harkamal Walia,

University of Nebraska Lincoln,

United States

Reviewed by:

Kazuo Nakashima,

Japan International Research Center

for Agricultural Sciences, Japan

Ratna Karan,

University of Florida, United States

*Correspondence:

Seong-Ryong Kim sungkim@sogang.ac.kr

Ki-Hong Jung

khjung2010@khu.ac.kr

Specialty section:

This article was submitted to

Plant Abiotic Stress,

a section of the journal

Frontiers in Plant Science

Received: 20 March 2017

Accepted: 09 June 2017

Published: 30 June 2017

Citation:

Kumar M, Gho Y-S, Jung K-H and

Kim S-R (2017) Genome-Wide Identification and Analysis of Genes,

Conserved between japonica

and indica Rice Cultivars, that Respond to Low-Temperature Stress at the Vegetative Growth Stage.

Front. Plant Sci. 8:1120. doi: 10.3389/fpls.2017.01120

\section{Genome-Wide Identification and Analysis of Genes, Conserved between japonica and indica Rice Cultivars, that Respond to Low-Temperature Stress at the Vegetative Growth Stage}

\author{
Manu Kumar', Yun-Shil Gho' ${ }^{2}$ Ki-Hong Jung ${ }^{2 *}$ and Seong-Ryong Kim ${ }^{1 *}$ \\ ${ }^{1}$ Department of Life Sciences, Sogang University, Seoul, South Korea, ${ }^{2}$ Graduate School of Biotechnology and Crop \\ Biotech Institute, Kyung Hee University, Yongin, South Korea
}

Cold stress is very detrimental to crop production. However, only a few genes in rice have been identified with known functions related to cold tolerance. To meet this agronomic challenge more effectively, researchers must take global approaches to select useful candidate genes and find the major regulatory factors. We used five Gene expression omnibus series data series of Affymetrix array data, produced with cold stress-treated samples from the NCBI Gene Expression Omnibus (http://www.ncbi.nlm.nih.gov/geo/), and identified 502 cold-inducible genes common to both japonica and indica rice cultivars. From them, we confirmed that the expression of two randomly chosen genes was increased by cold stress in planta. In addition, overexpression of OsWRKY71 enhanced cold tolerance in 'Dongjin,' the tested japonica cultivar. Comparisons between japonica and indica rice, based on calculations of plant survival rates and chlorophyll fluorescence, confirmed that the japonica rice was more cold-tolerant. Gene Ontology enrichment analysis indicate that the 'L-phenylalanine catabolic process,' within the Biological Process category, was the most highly overrepresented under cold-stress conditions, implying its significance in that response in rice. MapMan analysis classified 'Major Metabolic' processes and 'Regulatory Gene Modules' as two other major determinants of the cold-stress response and suggested several key cis-regulatory elements. Based on these results, we proposed a model that includes a pathway for cold stress-responsive signaling. Results from our functional analysis of the main signal transduction and transcription regulation factors identified in that pathway will provide insight into novel regulatory metabolism(s), as well as a foundation by which we can develop crop plants with enhanced cold tolerance.

Keywords: abiotic stress, cold stress, MapMan analysis, meta-expression analysis, Gene Ontology enrichment analysis, transcriptomics, rice, microarray 


\section{INTRODUCTION}

Agronomic productivity is declining due to various environmental problems, including cold stress. Crop yields are not sustainable when threatened by either chilling or freezing. The typical physiological response of a rice (Oryza sativa) plant exposed to such conditions is inhibited germination, followed by retarded seedling growth and restricted photosynthesis. Long periods of stress lead to chlorosis and tissue necrosis. Therefore, it is important that researchers improve their understanding of the regulatory mechanisms that can enhance cold tolerance.

The process of stress responses comprises perception of the low temperature, signal transduction, activation of TFs and stress-responsive genes, detoxification of reactive oxygen species (ROS), and initiation of repair systems. These steps make plants more tolerant to cold stress. Genetic and molecular studies have elucidated the functions of 59 such genes, for which information is now well-summarized in the OGRO database ${ }^{1}$ (Yamamoto et al., 2012). Many important crops, including rice, are sensitive to low temperatures and do not easily acclimatize during periods of cold stress. At the seedling stage, rice is more vulnerable, even to mild chilling. This can reduce overall growth and disrupt and delay the cycle of crop maturation, eventually decreasing yields (Zhang et al., 2014). The challenge of global warming means that crop plants, including rice, will be more exposed to extreme growing environments, e.g., low and high temperatures. Although the response by rice to cold stress has been described (Zhi-guo et al., 2014; Wang D. et al., 2016; Shakiba et al., 2017), we still need to identify more effective genes that can regulate this response.

Transcriptome analysis is a very powerful tool that provides the global view of a phenomenon and frequently suggests novel candidate genes for further study. Such analyses have been conducted to improve our understanding about the cold-stress response in rice. For example, (Zhang T. et al., 2012) have found more than 500 candidate genes that are significantly up-regulated under low temperatures. Moreover, 183 DEGs related to cold stress have been identified by Chawade et al. (2013), 383 DEGs by Yang et al. (2015), and more than 2000 DEGs by Zhao et al. (2014). Nevertheless, it has been difficult to determine from publicly available transcriptome data which of these candidate genes show consistent expression patterns under stress as well as across a range of cultivars.

Here, we focused on genes that are consistently up-regulated between japonica and indica cultivars under cold stress at the seedling stage. Our investigation utilized a large set of transcriptome data consisting of 27 japonica and 36 indica

Abbreviations: CREs, cis-regulatory elements; DAG, days after germination; DEG, differentially expressed gene; FASTA, Fast Alignment Search Tool; GEO, gene expression omnibus; GO, gene ontology; GUS, $\beta \beta$-glucuronidase; KMC, K-means clustering; MAST, Motif Alignment and Search Tool; Mev, Multiple Experiment Viewer; MS, Murashige and Skoog; NCBI, National Center for Biotechnology Information; OGRO, overview of functionally characterized genes in rice online database; Ox, overexpression; PPI, protein-protein interaction; RGAP, Rice Genome Annotation Project; TF, transcription factor; TOMTOM, TF-binding site motifs found by the motif comparison tool; WT, wild type.

${ }^{1}$ http://qtaro.abr.affrc.go.jp/ogro comparisons under low-temperature conditions, as obtained from the NCBI GEO (Barrett et al., 2011). From this, we identified 502 candidate genes that we further analyzed for their biological significance using GO term enrichment analysis and functional classifications via MapMan analysis ${ }^{2}$. We also selected two genes and confirmed their cold-inducible expression patterns using promoter-GUS trap systems. Based on those results, we proposed a novel promoter for further research applications to enhance cold tolerance. We then developed a hypothetical model to describe the signaling and transcriptional regulatory pathways that process the response to cold stress in rice.

\section{MATERIALS AND METHODS}

\section{Plant Materials and Stress Treatments}

Plants of japonica rice cv. Dongjin ('DJ') and indica rice 'IR64' ('IR64') were grown in a walk-in chamber (Koencon, Hanam, South Korea) under conditions of $30^{\circ} \mathrm{C}\left[200 \mu \mathrm{mol} \mathrm{m}^{-2} \mathrm{~s}^{-1}\right.$ (day) $] / 22^{\circ} \mathrm{C}$ (night) and a 12 -h photoperiod for 10 days in plastic boxes containing $100 \mathrm{~g}$ of soil used in growing rice (Punong, Kyung-Ju, Korea) (Kumar et al., 2017). The effects of cold stress (exposure at $4^{\circ} \mathrm{C}$ ) on the light intensity $110 \mu \mathrm{mol} \mathrm{m}{ }^{-2} \mathrm{~s}^{-1}$ were examined after exposure to cold stress for $0,24 \mathrm{~h} / 1$ day, $48 \mathrm{~h} / 2$ days, $72 \mathrm{~h} / 3$ days, $96 \mathrm{~h} / 4$ days, $120 \mathrm{~h} / 5$ days, and $144 \mathrm{~h} / 6$ days using chlorophyll fluorescence. Our mock treatment comprised a group of plants that remained at the normal growing temperature $\left(28^{\circ} \mathrm{C}\right)$ throughout the experimental period. To observe the physiological features of these seedlings, we used samples collected before cold stress was induced, as well as from plants after 4 days of stress, and then after recovery under normal conditions for 5 days. Fresh weights (FWs) were recorded after recovery from cold stress, and dry weights (DWs) were measured after the samples were dried at $80^{\circ} \mathrm{C}$ for 2 days.

\section{RT and qRT-PCR Analysis}

For monitoring the expression of cold-inducible marker genes, seedlings (selected at $10 \mathrm{DAG}$, or $10 \mathrm{DAG}$ ) were hydroponically cultured in Yoshida solution and exposed to $4^{\circ} \mathrm{C}$ for $0,1,3$, 6, 12, or $24 \mathrm{~h}$. Primers of OsZFP182/LOC_Os03g60560 and OsWYRKY71/LOC_Os02g08440 were used for RT and qRT-PCR analyses at a final concentration of $10 \mathrm{pmol}$, with $3 \mu \mathrm{L}$ (equivalent to $30 \mathrm{ng}$ of total RNA) of cDNA as template (Supplementary Table S1). The internal controls were primers of rice ubiquitin 5 (OsUbi5) and rice actin 1 (RAc1) (Supplementary Table S1). An RNeasy Mini Plant Kit (Qiagen, Germany) was used for total RNA isolation and an RT Complete Kit (Biofact, Korea) was used for cDNA synthesis according to the manufacturers' instructions. Primers were designed with Gene Runner software ${ }^{3}$ and NCBI primer blast $t^{4}$. The amplified products were resolved on a $1 \%$ agarose gel.

\footnotetext{
${ }^{2}$ http://mapman.gabipd.org

${ }^{3} \mathrm{http}: / /$ www.generunner.net/

${ }^{4}$ http://www.ncbi.nlm.nih.gov/tools/primer-blast/
} 


\section{Measurement of $\mathrm{H}_{2} \mathrm{O}_{2}$}

An uptake assay was conducted to determine the relative concentration of $\mathrm{H}_{2} \mathrm{O}_{2}$, using Amplex ${ }^{\circledR}$ Red reagent (10-acetyle3, 7dihydroxyphenoxazine; Molecular Probes/Invitrogen, United

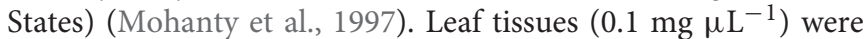
homogenized in a standard MS medium (Murashige and Skoog, 1962) and then incubated under darkness for $30 \mathrm{~min}$ with horseradish peroxidase $\left(0.2 \mathrm{U} \mathrm{mL}^{-1}\right)$ and Amplex ${ }^{\circledR}$ Red reagent $(1 \mu \mathrm{M})$. The $\mathrm{H}_{2} \mathrm{O}_{2}$ released from these tissues was detected by a SpectraMax 250 Microplate Reader (Molecular Devices Inc., United States) with absorbance measured at $560 \mathrm{~nm}$ (Kumar et al., 2014).

\section{Meta-Expression Analysis}

We downloaded raw data for five GSE data series (i.e., GEO accession number GSE6901, GSE33204, GSE37940, GSE38023, and GSE31077) that are related to cold-stress responses, as indicated from the NCBI GEO ${ }^{5}$ (Barrett et al., 2011). Details are presented in Supplementary Table S2. The data were normalized using an Affy Package encoded by $\mathrm{R}$ language, and the intensity values were transformed into the $\log _{2}$ scale as we have previously described (Cao et al., 2012). This allowed us to generate $\log _{2}$ fold-change values for cold-stressed samples. Similar fold-changes were revealed for other stress conditions. For each data series, we used those fold-change data to perform a KMC analysis to identify genes that were consistently up-regulated under all cold-stress conditions. The KMC analysis of meta-expression data for abiotic stresses - salt, drought, cold, heat, submergence, and anaerobic conditions grouped all of the candidate genes into 12 clusters. From these, we selected 502 genes that were up-regulated by coldstress treatment but not during the recovery period. Heatmap images were produced using $\mathrm{Mev}$ software (Chu et al., 2008).

\section{GUS Assays and Co-segregation Test of Promoter Trap Lines}

To examine GUS expression patterns, we germinated seeds from two promoter trap lines in an MS medium for 7 days. These lines were obtained from a mixed pool of PFG T-DNA tagging lines from POSTECH in Korea (Lee et al., 2004; Jung et al., 2005, 2006, 2015; Hong et al., 2017; Wei et al., 2017). The resultant plantlets were then exposed to cold stress $\left(4^{\circ} \mathrm{C}\right)$ for 0 or $24 \mathrm{~h}$. Afterward, whole seedlings from all treatment groups were soaked for $8 \mathrm{~h}$ in a GUS-staining solution before their roots were photographed with a camera (Canon EOS 550D; Cannon, Tokyo, Japan).

\section{Analysis of Cis-Regulatory Elements}

To identify any consensus CREs in the promoters of our cold-inducible genes, we extracted $2-\mathrm{kb}$ upstream sequences of ATG for LOC_Os01g31370 and LOC_Os03g49830, which were validated in our current GUS assays. We also used the sequence for LOC_Os10g41200, which was previously reported to be a coldinducible promoter based on the promoter-GUS system (Rerksiri

${ }^{5}$ http://www.ncbi.nlm.nih.gov/geo/ et al., 2013; Jeong and Jung, 2015) from PLANTPAN ${ }^{6}$ (Chang et al., 2008). Several MEME searches were performed with those sequences in the FASTA format via the Web server hosted by the National Biomedical Computation Resource ${ }^{7}$. We looked for up to five CREs with an option of 12 maximum motif widths. Using the MAST, we then searched DNA sequences for matches to the putative TOMTOM within a set of promoter sequences (Bailey et al., 2006).

\section{Analysis of Gene Ontology Enrichment}

To analyze the biological significance of selected candidate genes, we employed the GO enrichment tool installed in the Rice Oligonucleotide Array Database ${ }^{8}$ (Jung et al., 2008a; Cao et al., 2012). For this, we uploaded 502 genes showing upregulation in both japonica and indica cultivars under cold stress. A fold-enrichment value higher than the standard (' 1 ') meant that the selected GO term was over-represented more than was expected. Terms with $>2$-fold enrichment values and $p$-values $<0.05$ were also used as criteria for choosing the most significant GO terms in the 'Biological Process' category.

\section{MapMan Analysis}

The rice MapMan classification system covers 36 BINs, each of which can be extended in a hierarchical manner into subBINs (Usadel et al., 2005; Urbanczyk-Wochniak et al., 2006). By applying diverse MapMan tools, a significant gene list selected from high-throughput data analysis can be integrated to diverse overviews. Here, we uploaded locus IDs from the RGAP for 502 DEGs with a value of ' 3 ', which indicated upregulation under cold stress. Finally, we used four overviews - Metabolism, Regulation, Transcription, and Proteasome - installed in the MapMan toolkit.

\section{Analysis of Rice Genes with Known Functions}

To evaluate the functional significance of our candidate genes, we compared our list with the one from OGRO, which summarizes rice genes with known functions (Table 1; Yamamoto et al., 2012).

\section{Evaluation of Cold Tolerance in a Line Over-Expressing OsWYRKY71}

Plants from an Ox line for OsWYRKY71 (OsWYRKY71-Ox) under the control of CaMV35S promoter (Kim et al., 2016) and from the WT (Japonica cv. Dongjin) were grown for 10 days in plastic boxes containing soil. To test their tolerance, we then exposed them to cold stress $\left(4^{\circ} \mathrm{C}\right)$ for 5 days and then returned them to normal growing conditions for 6 days of recovery. Survival rates were determined at the end of this experimental period. Cold stress analysis of OsWYRKY71-Ox lines was done with three replicates.

\footnotetext{
${ }^{6} \mathrm{http}: / /$ plantpan2.itps.ncku.edu.tw/

${ }^{7}$ http://www.nbcr.net/

${ }^{8} \mathrm{http}: / /$ www.ricearray.org/analysis/go_enrichment.shtml
} 
TABLE 1 | Rice genes functionally characterized as cold-inducible.

\begin{tabular}{|c|c|c|c|c|c|c|c|}
\hline Gene & Major_F & Minor_F & RAP-DB_ID & MSU_ID & Method & Detailed functions & Reference \\
\hline ZFP182 & $R / T$ & Cold T & Os03g0820300 & LOC_Os03g60560.1 & OX & Cold, drought, and salinity T. & Huang et al., 2012 \\
\hline OsDREB1A & $\mathrm{R} / \mathrm{T}$ & Cold T & Os09g0522200 & LOC_Os09g35030.1 & OX & Cold, drought, and salinity T. & Ito et al., 2006 \\
\hline OsWRKY45 & $R / T$ & Cold T & Os05g0322900 & LOC_Os05g25770.1 & $\mathrm{Kd} \mathrm{OX}$ & $\begin{array}{l}\text { Cold, drought, and salinity } \mathrm{T} ; \mathrm{ABA} \\
\text { sensitivity. }\end{array}$ & Tao et al., 2011 \\
\hline OsWRKY76 & $R / T$ & Cold T & Os09g0417600 & LOC_Os09g25060.1 & OX & R to Magnaporthe oryzae; cold T. & $\begin{array}{l}\text { Yokotani et al., } \\
2013\end{array}$ \\
\hline OsMYB2 & $R / T$ & Cold T & Os03g0315400 & LOC_Os03g20090.1 & OX & $\begin{array}{l}\text { Cold, drought, and salinity } \mathrm{T} ; \mathrm{ABA} \\
\text { sensitivity. }\end{array}$ & Yang et al., 2012 \\
\hline OsCAF1B & $R / T$ & Cold T & Os04g0684900 & LOC_Os04g58810.1 & Others & Cold T & Chou et al., 2014 \\
\hline OsSPX1 & $R / T$ & Cold T & Os06g0603600 & LOC_Os06g40120.1 & $\mathrm{Kd}$ & Cold and oxidative stresses $\mathrm{T}$. & $\begin{array}{l}\text { Wang C. et al., } \\
2013\end{array}$ \\
\hline OSDREB1C & $R / T$ & Drought $\mathrm{T}$ & Os06g0127100 & LOC_Os06g03670.1 & OX & Cold, drought, and salinity T. & Ito et al., 2006 \\
\hline ZFP182 & $\mathrm{R} / \mathrm{T}$ & Drought $\mathrm{T}$ & Os03g0820300 & LOC_Os03g60560.1 & OX & Cold, drought, and salinity T. & Huang et al., 2012 \\
\hline OsSRO1c & $R / T$ & Drought $\mathrm{T}$ & Os03g0230300 & LOC_Os03g12820.1 & Mutant & Stomatal control; oxidative stress $R$. & You et al., 2013 \\
\hline OsDREB1B & $R / T$ & Drought $\mathrm{T}$ & Os09g0522000 & LOC_Os09g35010.1 & OX & Cold, drought, and salinity T. & Ito et al., 2006 \\
\hline OsDREB1A & $\mathrm{R} / \mathrm{T}$ & Drought $\mathrm{T}$ & Os09g0522200 & LOC_Os09g35030.1 & OX & Cold, drought, and salinity T. & Ito et al., 2006 \\
\hline OsWRKY45 & $R / T$ & Drought $\mathrm{T}$ & Os05g0322900 & LOC_Os05g25770.1 & $\mathrm{Kd} \mathrm{OX}$ & $\begin{array}{l}\text { Cold, drought, and salinity T; ABA } \\
\text { sensitivity. }\end{array}$ & Tao et al., 2011 \\
\hline OsMYB2 & $R / T$ & Drought $\mathrm{T}$ & Os03g0315400 & LOC_Os03g20090.1 & OX & $\begin{array}{l}\text { Cold, drought, and salinity T; ABA } \\
\text { sensitivity. }\end{array}$ & Yang et al., 2012 \\
\hline OsCPK4 & $R / T$ & Drought $T$ & Os02g0126400 & LOC_Os02g03410.1 & $\mathrm{Kd}$ & $\begin{array}{l}\text { Protection of cellular membrane } \\
\text { from drought stress. }\end{array}$ & Campo et al., 2014 \\
\hline OsERF3 & $R / T$ & Drought $\mathrm{T}$ & Os01g0797600 & LOC_Os01g58420.1 & OX & $\begin{array}{l}\text { Drought } \mathrm{T} \text { by controlling ethylene } \\
\text { biosynthesis. }\end{array}$ & Wan et al., 2011 \\
\hline OsAP2-39 & $R / T$ & Drought $\mathrm{T}$ & Os04g0610400 & LOC_Os04g52090.1 & OX & Dwarfism; fertility; and drought $\mathrm{T}$. & Yaish et al., 2010 \\
\hline OsDREB1C & $R / T$ & Salinity $T$ & Os06g0127100 & LOC_Os06g03670.1 & OX & Cold, drought, and salinity T. & Ito et al., 2006 \\
\hline OSEATB & $R / T$ & Salinity $T$ & Os09g0457900 & LOC_Os09g28440.1 & OX & $\begin{array}{l}\text { Internode elongation; panicle } \\
\text { branching; tillering; salinity T. }\end{array}$ & Qi et al., 2011 \\
\hline ZFP182 & $R / T$ & Salinity $T$ & Os03g0820300 & LOC_Os03g60560.1 & OX & Cold, drought, and salinity T. & Huang et al., 2012 \\
\hline ZFP179 & $R / T$ & Salinity $T$ & Os01g0839100 & LOC_Os01g62190.1 & OX & Salinity and oxidative stress T. & Sun et al., 2010 \\
\hline OsDREB1B & $R / T$ & Salinity $T$ & Os09g0522000 & LOC_Os09g35010.1 & OX & Cold, drought, and salinity T. & Ito et al., 2006 \\
\hline OsDREB1A & $R / T$ & Salinity $T$ & Os09g0522200 & LOC_Os09g35030.1 & OX & Cold, drought, and salinity T. & Ito et al., 2006 \\
\hline OsWRKY45 & $R / T$ & Salinity $T$ & Os05g0322900 & LOC_Os05g25770.1 & $\mathrm{Kd} \mathrm{OX}$ & $\begin{array}{l}\text { Cold, drought, and salinity T; ABA } \\
\text { sensitivity. }\end{array}$ & Tao et al., 2011 \\
\hline OsTPP1 & $R / T$ & Salinity $T$ & Os02g0661100 & LOC_Os02g44230.1 & OX & Cold and salinity $T$. & Ge et al., 2008 \\
\hline OsMYB2 & $R / T$ & Salinity $T$ & Os03g0315400 & LOC_Os03g20090.1 & OX & $\begin{array}{l}\text { Cold, drought, and salinity T; ABA } \\
\text { sensitivity. }\end{array}$ & Yang et al., 2012 \\
\hline OSMAPK5 & $R / T$ & Salinity $T$ & Os03g0285800 & LOC_Os03g17700.1 & $\mathrm{Kd} \mathrm{OX}$ & $\begin{array}{l}\text { R to Magnaporthe grisea and } \\
\text { Burkholderia glumae; cold, drought, } \\
\text { and salinity T. }\end{array}$ & $\begin{array}{l}\text { Xiong and Yang, } \\
2003\end{array}$ \\
\hline
\end{tabular}


TABLE 1 | Continued

\begin{tabular}{|c|c|c|c|c|c|c|c|}
\hline Gene & Major_F & Minor_F & RAP-DB_ID & MSU_ID & Method & Detailed functions & Reference \\
\hline OsCDPK7 & $R / T$ & Salinity $T$ & Os04g0584600 & LOC_Os04g49510.1 & OX & Drought and salinity $\mathrm{T}$. & Saijo et al., 2000 \\
\hline OsPLDbeta1 & $R / T$ & Blast $\mathrm{R}$ & Os10g0524400 & LOC_Os10g38060.1 & $\mathrm{Kd}$ & $\begin{array}{l}\mathrm{R} \text { to Pyricularia grisea and } \\
\text { Xanthomonas oryzae pv. oryzae. }\end{array}$ & $\begin{array}{l}\text { Yamaguchi et al., } \\
2009\end{array}$ \\
\hline OsAOS2 & $R / T$ & Blast R & Os03g0225900 & LOC_Os03g12500.1 & OX & R to Magnaporthe grisea. & Mei et al., 2006 \\
\hline OsWRKY76 & $R / T$ & Blast R & Os09g0417600 & LOC_Os09g25060.1 & OX & R to Magnaporthe oryzae; cold T. & $\begin{array}{l}\text { Yokotani et al., } \\
2013\end{array}$ \\
\hline OSMAPK5 & $R / T$ & Blast R & Os03g0285800 & LOC_Os03g17700.1 & $\mathrm{Kd} \mathrm{OX}$ & $\begin{array}{l}\text { R to Magnaporthe grisea and } \\
\text { Burkholderia glumae; cold, drought, } \\
\text { and salinity T. }\end{array}$ & $\begin{array}{l}\text { Xiong and Yang, } \\
2003\end{array}$ \\
\hline OsWRKY76 & $R / T$ & Bacterial blight $\mathrm{R}$ & Os09g0417600 & LOC_Os09g25060.1 & OX & $\begin{array}{l}\text { R to Xanthomonas oryzae pv. } \\
\text { oryzae. }\end{array}$ & $\begin{array}{l}\text { Yokotani et al., } \\
2013\end{array}$ \\
\hline OsMAPK5 & $R / T$ & Bacterial blight $R$ & Os03g0285800 & LOC_Os03g17700.1 & $\mathrm{Kd} \mathrm{OX}$ & $\begin{array}{l}\text { R to Magnaporthe grisea and } \\
\text { Burkholderia glumae; cold, drought, } \\
\text { and salinity T. }\end{array}$ & $\begin{array}{l}\text { Xiong and Yang, } \\
2003\end{array}$ \\
\hline OsNAC4 & $R / T$ & Bacterial blight $R$ & Os01g0816100 & LOC_Os01g60020.1 & $\mathrm{Kd}$ & Bacterial blight R; HR cell death. & Kaneda et al., 2009 \\
\hline OsWRKY71 & $R / T$ & Bacterial blight $R$ & Os02g0181300 & LOC_Os02g08440.1 & OX & $\begin{array}{l}\text { R to Xanthomonas oryzae pv. } \\
\text { oryzae. }\end{array}$ & Liu et al., 2007 \\
\hline OsHI-LOX & $R / T$ & Insect R & Os08g0508800 & LOC_Os08g39840.1 & $\mathrm{Kd}$ & $\begin{array}{l}\mathrm{R} \text { to rice striped stem borer and } \\
\text { rice brown planthopper. }\end{array}$ & Zhou et al., 2009 \\
\hline OsCAF1B & $R / T$ & Other stress $\mathrm{R}$ & Os04g0684900 & LOC_Os04g58810.1 & Others & Wounding; ABA T. & Chou et al., 2014 \\
\hline OsSPX1 & $R / T$ & Other stress $R$ & Os06g0603600 & LOC_Os06g40120.1 & $\mathrm{Kd}$ & Cold and oxidative stress $\mathrm{T}$. & $\begin{array}{l}\text { Wang C. et al., } \\
2013\end{array}$ \\
\hline ZFP179 & $R / T$ & Other soil stress $T$ & Os01g0839100 & LOC_Os01g62190.1 & OX & Salinity and oxidative stress $\mathrm{T}$. & Sun et al., 2010 \\
\hline OsSPX1 & $R / T$ & Other soil stress $T$ & Os06g0603600 & LOC_Os06g40120.1 & OX & Phosphate homeostasis. & $\begin{array}{l}\text { Wang C. et al., } \\
2013\end{array}$ \\
\hline OsEATB & MT & Dwarf & Os09g0457900 & LOC_Os09g28440.1 & OX & $\begin{array}{l}\text { Internode elongation; panicle } \\
\text { branching; tillering; salinity T. }\end{array}$ & Qi et al., 2011 \\
\hline OsPHI-1 & MT & Dwarf & Os02g0757100 & LOC_Os02g52040.1 & $\mathrm{Kd}$ & Dwarfism. & Aya et al., 2014 \\
\hline OsMPS & MT & Dwarf & Os02g0618400 & LOC_Os02g40530.1 & $\mathrm{Kd} \mathrm{OX}$ & Grain size; total biomass. & $\begin{array}{l}\text { Schmidt et al., } \\
2013\end{array}$ \\
\hline RERJ1 & MT & Dwarf & Os04g0301500 & LOC_Os04g23550.1 & $\mathrm{Kd} \mathrm{OX}$ & $\begin{array}{l}\text { Dwarfism; JA sensitivity during } \\
\text { seedling stage. }\end{array}$ & $\begin{array}{l}\text { Kiribuchi et al., } \\
2004\end{array}$ \\
\hline GA2OX3 & MT & Dwarf & Os01g0757200 & LOC_Os01g55240.1 & Others & Dwarfism; gibberellin catabolism. & Lo et al., 2008 \\
\hline TIFY11b & MT & Dwarf & Os03g0181100 & LOC_Os03g08330.1 & OX & Grain size; plant height. & Hakata et al., 2012 \\
\hline OsDOG & MT & Dwarf & Os08g0504700 & LOC_Os08g39450.1 & OX & $\begin{array}{l}\text { Dwarfism; cell elongation; } \\
\text { regulation of gibberellin } \\
\text { biosynthesis. }\end{array}$ & Liu et al., 2011 \\
\hline OsBZR1 & MT & Dwarf & Os07g0580500 & LOC_Os07g39220.1 & $\mathrm{Kd}$ & $\begin{array}{l}\text { Dwarfism; leaf angle; } \\
\text { brassinosteroid sensitivity. }\end{array}$ & Bai et al., 2007 \\
\hline gid1 & MT & Dwarf & Os05g0407500 & LOC_Os05g33730.1 & Mutant & Dwarfism; gibberellin sensitivity. & $\begin{array}{l}\text { Ueguchi-Tanaka } \\
\text { et al., } 2005\end{array}$ \\
\hline
\end{tabular}


TABLE 1 | Continued

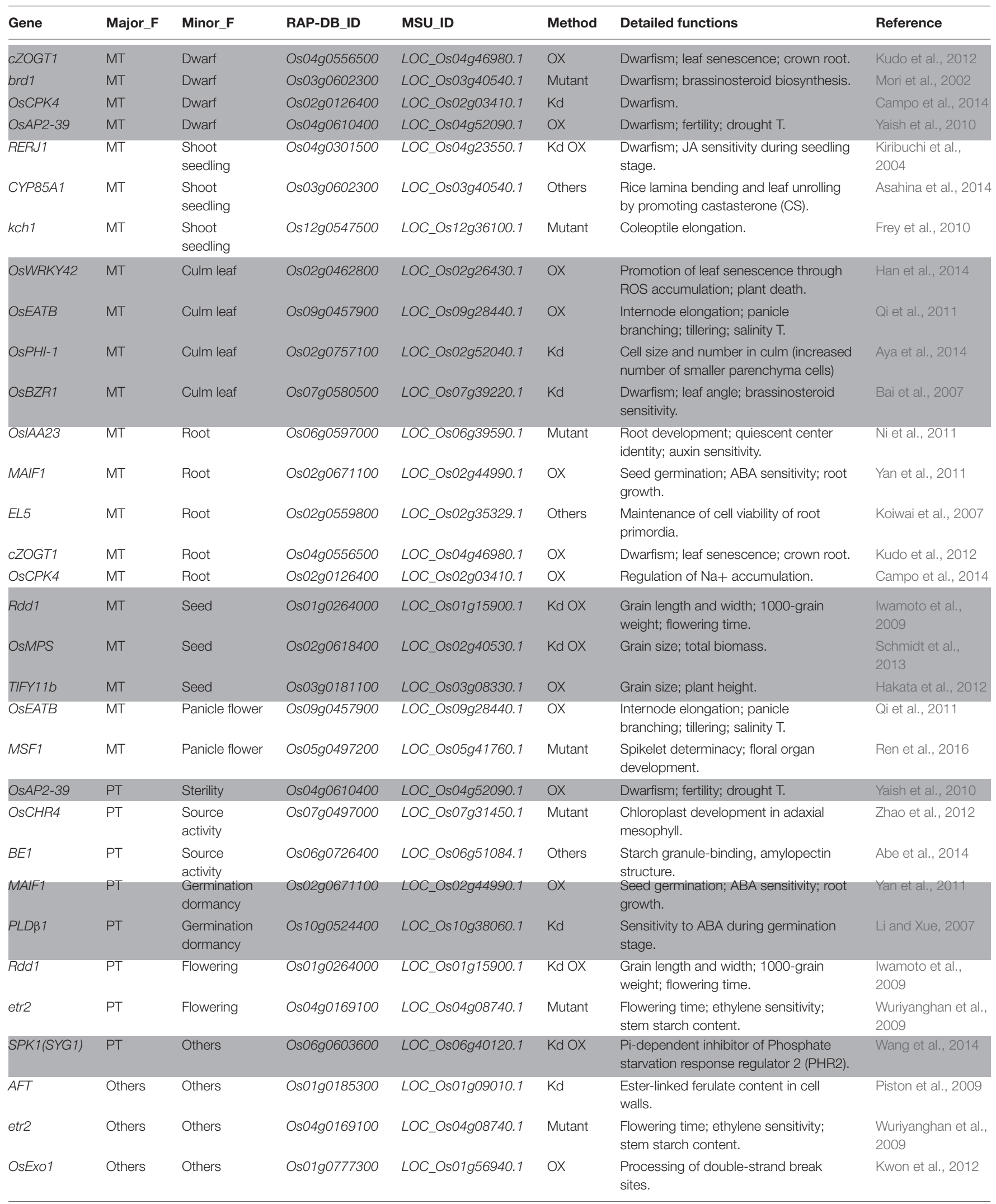

$R$, resistant; T, tolerant; MT, morphological trait; OX, overexpression; Kd, knockdown. 
A

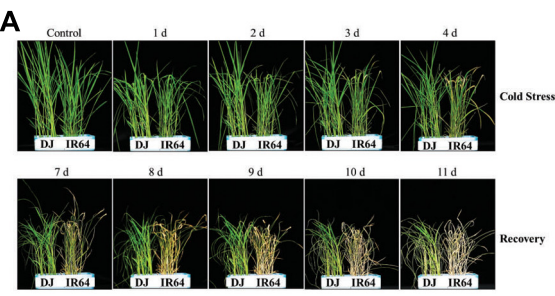

B

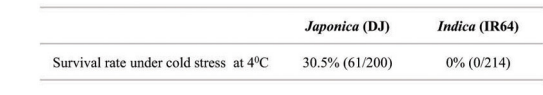

C

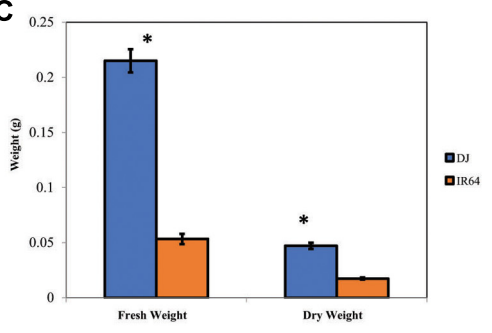

D

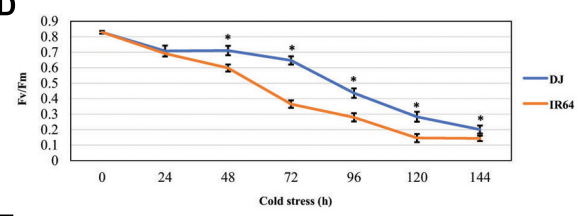

E

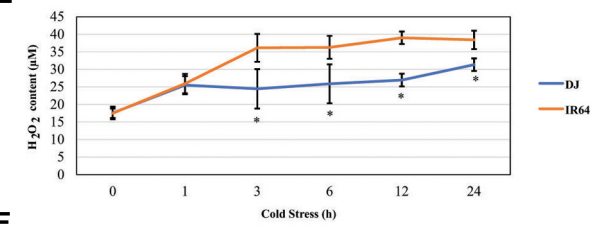

F
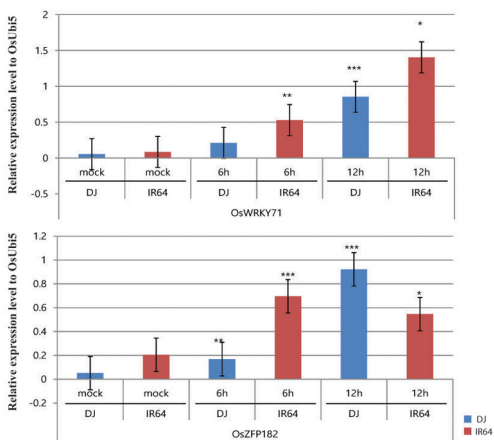

FIGURE 1 | Analysis of cold stress responses by japonica and indica rice cultivars. (A) Phenotypes associated with cold-stress response by 'DJ' and 'IR64' rice seedlings observed during treatment for 4 days followed by 5 days of recovery. (B) Tolerance of seedlings based on survival rates. (C) Fresh and dry weights after recovery from cold stress. (D) Photosynthetic efficiency $\left(F_{\mathrm{v}} / F_{\mathrm{m}}\right)$ after cold treatment for 4 days. (E) Determination of $\mathrm{ROS}$ concentrations (i.e., levels of $\left.\mathrm{H}_{2} \mathrm{O}_{2}\right)$ in seedlings after cold treatment for $24 \mathrm{~h}$. (F) Expression of 2 marker genes (OsZFP182 and OsWRKY71) in stressed seedlings, using OsUbi5 as an internal control. ***, $p$-value $<0.001,{ }^{* *}, 0.001<p$-value $<0.01 ;{ }^{*}, 0.01<p$-value $<0.05$.

\section{RESULTS AND DISCUSSION}

\section{Physiological Responses of \\ Cold-Stressed Rice Seedlings}

Cold stress adversely affects plant growth and yield, and rice isparticularly susceptible at the seedling stage (Zhang et al., 2014). Ouranalysis involved 10-day-old 'DJ' (japonica) and 'IR64'(indica) plants exposed to $4^{\circ} \mathrm{C}$ for 4 days.Afterward, they recovered for 5 days at $28^{\circ} \mathrm{C}$. Their phenotypes are shown in Figure 1A. At the end of this experimental period, the survival rate was $30.5 \%$ for 'DJ' versus $0.0 \%$ for 'IR64,'indicating that the former was more old-tolerant (Figure 1B). The $F_{\mathrm{W}}$ value was $162 \mathrm{mg}$ higher for ' $\mathrm{DJ}$ ' while its DW was $29 \mathrm{mg}$ higher than for 'IR64' (Figure 1C). Prolonged cold stress also negatively affected photosynthetic efficiency, with both cultivars showing significant reductions after $24 \mathrm{~h}$ (Figure 1D). The decline in efficiency after $48 \mathrm{~h}$ was more severe for 'IR64' than for 'DJ.'

The accumulation of ROS, including $\mathrm{H}_{2} \mathrm{O}_{2}$, is a major indicator of the plant response to various abiotic stresses. We found that 'IR64' had higher $\mathrm{H}_{2} \mathrm{O}_{2}$ concentrations than did 'DJ' after 3 and $24 \mathrm{~h}$ of cold treatment (Figure 1E).

We also evaluated the expression patterns of two well-known cold stress-responsible genes, OsZFP182 and OsWRKY71 (Huang et al., 2007; Kim et al., 2016) and found that, as expected, their expression was significantly induced, and to nearly the same extent, in both cultivars (Figure 1F). This demonstrated that the tool of global transcriptome data can be broadly applied for determining and, ultimately, improving cold tolerance in rice.

\section{Genome-Wide Identification of Cold Stress-Inducible Genes in Both japonica and indica Cultivars Using Meta-Expression Data Analysis}

As a quantitative trait, tolerance to cold stress is governed by different sets of genes, and through diverse mechanisms. We used meta-expression analysis with transcriptome data and downloaded information about global candidate genes from the NCBI GEO for series GSE37940 and GSE38023 (Zhang F. et al., 2012; Zhang H. et al., 2012). After normalizing these data, we generated 63 comparisons for cold-stress treatment, as well as 49 comparisons for drought stress, 6 for high temperatures, and 4 for submergence (Supplementary Table S2). Our KMC analysis with the resultant fold-change data revealed 502 genes that were significant up-regulated upon cold stress but not under recovery conditions (Figure 2). From this, we prepared 27 comparisons with two japonica cultivars - 'C418' (a japonica restorer line for hybrid rice production and cold sensitive) and 'Li-JiangXin-Tuan-Hei-Gu' ('LTH,' cold tolerant genotype) - and 36 comparisons with five indica cultivars - 'IR24' (photoperiodinsensitive, high yielding and cold sensitive variety), 'IR64' 


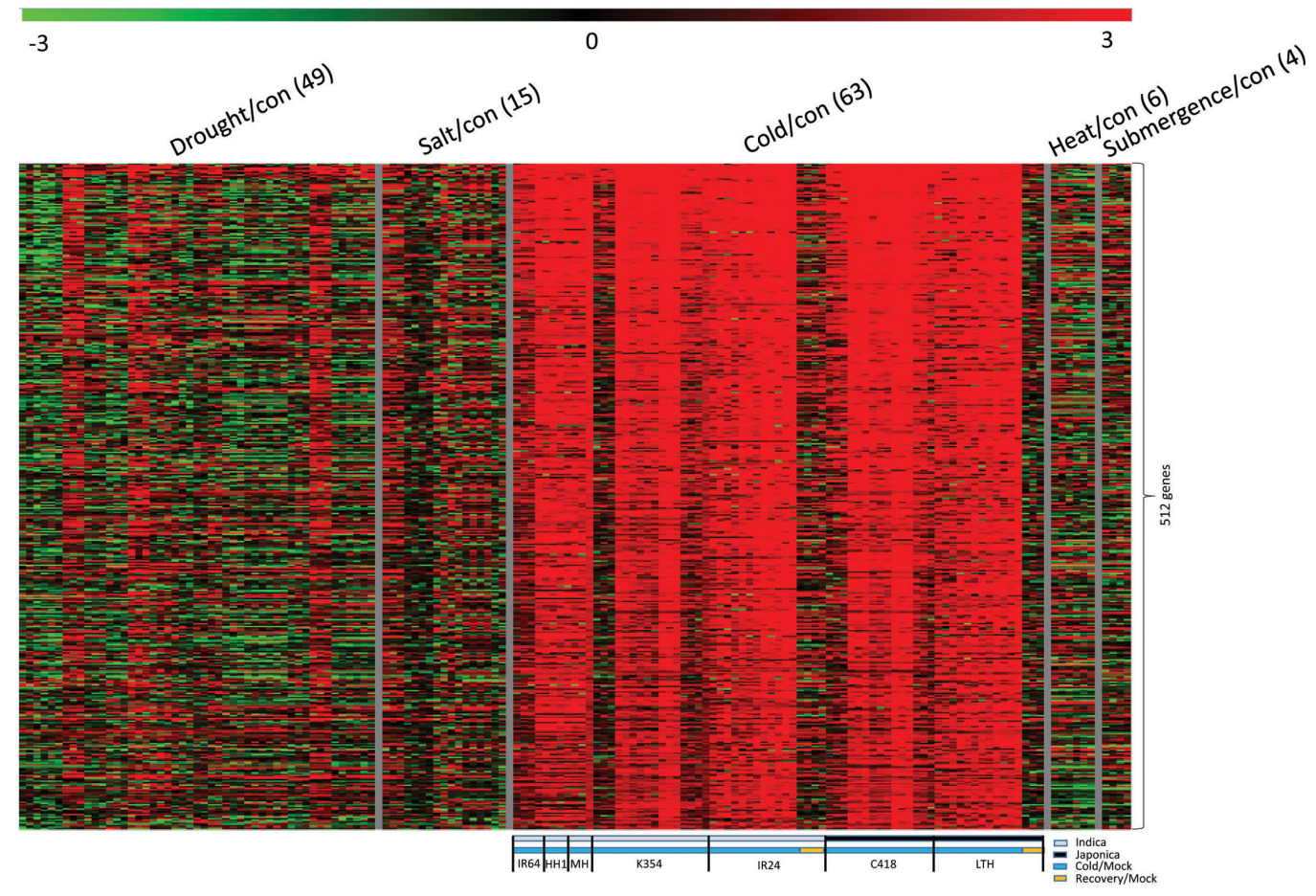

FIGURE 2 | Heatmap of genes up-regulated under stress in both japonica and indica cultivars. Panel above heatmap indicates type of abiotic stress applied; parentheses indicate number of stress/control in each treatment. Panel below heatmap shows detailed information for "main target" samples under cold stress. Gray box, indica cultivars; black, japonica cultivars; blue, cold stress/control; and brown, recovery/control. Indica cultivars: 'IR64,' 'Huahui 1' ('HH1'), 'Minghui 63' ('MH'), 'K354,' and 'IR24'; japonica cultivars: 'C418' and 'Li-Jiang-Xin-Tuan-Hei-Gu' ('LTH').

[variety with moderate tolerance toward toxicity in response to various molecules including salt, alkali, iron, and boron as well as deficiencies in phosphorus and zinc, but sensitivity to cold stress], 'K354' (a BC2F6 introgression line as a progeny of C418 and cold tolerant variety), 'Huahui 1' ('HH1,' insect-resistant variety as a progeny of Minghui 63), and 'Minghui 63' ('MH', heat tolerant variety and a parental line of $\mathrm{HH} 1$ ). Their upregulation was conserved between japonica and indica cultivars. All of these genes provide potential for a broader range of applications to enhance cold tolerance in rice. These 502 DEGs were used for further analysis of the cold-stress response (Supplementary Table S3).

\section{Validation of Cold-Inducible Genes in Rice Roots Using the GUS Reporter System and qRT-PCR}

Promoter traps employing the GUS reporter gene system have been used to identify promoters involved in regulating tissuespecific and stress-responsive expression patterns (Jung et al., 2005, 2006). Our meta-expression analysis identified the top 50 genes showing $>3.5$-fold upregulation by cold stress when compared with the control (Supplementary Table S3). We then searched and identified 52 potential promoter trap lines of 43 candidate genes and examined GUS expression patterns in 7-day-old seedlings. The lines for two genes (PFG 3A-50649 for LOC_Os01g31370 and PFG 1C-08613 for LOC_Os03g49830) displayed GUS expression in the roots after plants were exposed to stress for $24 \mathrm{~h}$ (Figure 3 and Supplementary Figure S1). This cold-related expression was also verified by qRT-PCR (Supplementary Figure S1). Previous studies using a promoterGUS vector or promoter trap system have confirmed the upregulation of LOC_Os10g41200 in response to cold stress (Su et al., 2010; Jeong and Jung, 2015). Our findings demonstrated that the promoter trap system, when combined with qualified genome-wide transcriptome data, is a very effective way for quickly identifying the activity of an endogenous promoter. This enables researchers to develop novel promoters for future applications.

\section{Analysis of Cis-Regulatory Elements Conserved in Promoters of Three Cold-Inducible Genes Confirmed by the GUS Reporter System}

To identify the cis-regulatory regulatory elements (CREs) associated with the response to cold, we used promoter regions in 2-kb sequences upstream of ATG of the two cold-inducible genes (LOC_Os01g31370 and LOC_Os03g49830) that had been validated through GUS trap assays and also included the promoter region of LOC_Oslog41200, which have previously been reported as a cold-inducible gene using GUS reporter systems (Su et al., 2010; Rerksiri et al., 2013; Jeong and Jung, 2015). Through in silico analysis of CREs, we revealed the 

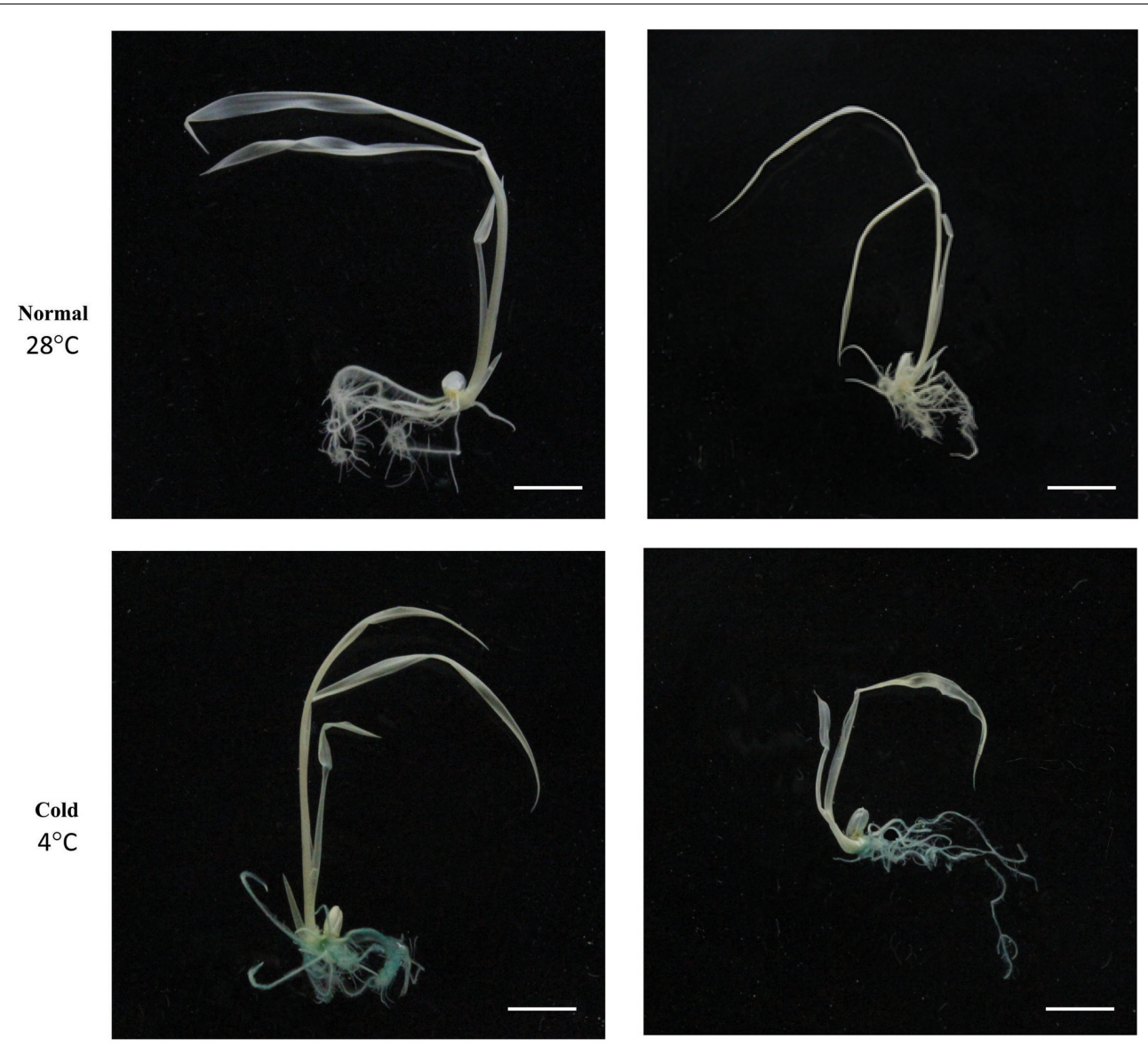

pLOC_Os03g49830::GUS

pLOC_Os01g31370::GUS

FIGURE 3 | Validation of expression patterns for two cold stress-responsive genes using GUS reporter systems. Promoter trap lines using GUS reporter gene were selected and tested for GUS activity. Promoter trap line for LOC_Os01g31370, Line PFG 3A-50649 (right), and that of LOC_Os03g49830, Line PFG 1C-08613 (left) were confirmed through co-segregation test of GUS expression and T-DNA insertion through genotyping analysis. Upper panel, GUS-staining data from promoter trap lines under normal growing conditions; lower panel, lines under cold-stress conditions. Homozygous progeny of T-DNA insertion for each of two lines were used.

presence of common 51 CREs in the promoter regions from the PLANTPAN 2.0 database9 (Chow et al., 2016) and MEME tool $^{10}$ (Bailey et al., 2006). Selected promoter regions and CREs are summarized in Supplementary Table S4. Of these, we have more interest in five unique CREs: DRECRTCOREAT (RCCGAC), ABREMOTIFIOSRAB16B (AGTACGTGGC), ABADESI2 (GGACGCGTGGC), GARE2OSREP1 (TAACGTA), and ANAERO3CONSENSUS (TCATCAC) (Figure $\mathbf{4}$ and Supplementary Table S4). DRECRTCOREAT is a core motif of dehydration-responsive element/C-repeat (DRE/CRT) found in the promoters of genes from various species. Previous studies reported that OsDREB1A, AtDREB1A and ZmDREB1A bound to (G/ACCGAC) with the different efficiency by competitive DNA binding assays (Sakuma et al., 2002; Dubouzet et al., 2003; Qin et al., 2004) and OsDREB gene encodes transcription activators that function in drought, salt and cold-responsive gene expression (Dubouzet et al., 2003). However, although the

\footnotetext{
${ }^{9} \mathrm{http}: / /$ plantpan2.itps.ncku.edu.tw

${ }^{10} \mathrm{http}: / /$ meme-suite.org/
}

Aloe DREB1 can bind to the DRE, it may also bind to other CREs effectively, which can function in a new cold-induced signal transduction pathway (Wang and $\mathrm{He}, 2007$ ). It has been known that phytohormones including $\mathrm{ABA}$, auxin, gibberellic acid (GA), salicylic acid (SA) and ethylene are related to the cold responses positively or negatively (Miura and Furumoto, 2013; Verma et al., 2016). Among the ABA-responsive CREs, we found that ABREMOTIFIOSRAB16B and ABADESI2 earlier identified from rice Osrab16B promoter and wheat histone $\mathrm{H} 3$ promoter were related to ABA-regulated transcription (Terada et al., 1993; Ono et al., 1996; Busk and Pagès, 1998). In addition, GARE1OSREP1 is involved in Gibberellin-responsive element (GARE) found in rice OsREP-1 promoter (Ogawa et al., 2003; Sutoh and Yamauchi, 2003). ANAERO3CONSENSUS found in promoters of anaerobic genes is involved in the fermentative pathway and related to anaerobic response (Mohanty et al., 2005). In summary, DRECRTCOREAT might be related to coldpreferred expression, and ABREMOTIFIOSRAB16B, ABADESI2 and GARE1OSREP1 might be associated with crosstalk between phytohormones and cold stress-preferred expression. The other 


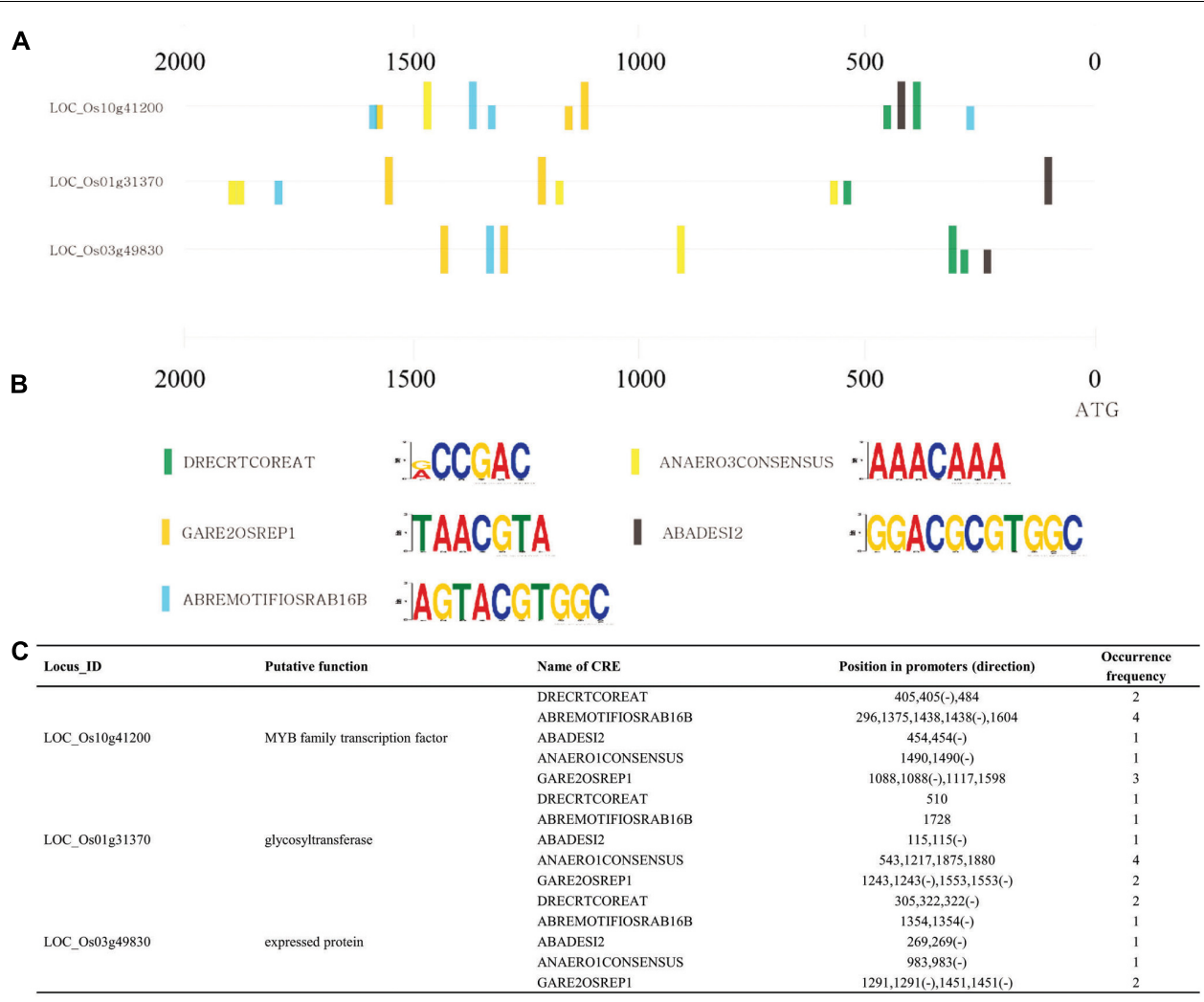

FIGURE 4 | Identification of CREs conserved in three cold-inducible genes. Consensus CREs in promoters of cold-inducible genes were studied with GUS reporter systems, using 2-kb upstream sequences of ATG for LOC_Os01g31370, LOC_Os03g49830, and LOC_Os10g41200 to confirm cold induction in planta.

(A) Distribution of five CREs conserved in promoters of three cold-inducible genes but not in those of randomly selected genes. (B) Names and conserved sequences presented using MEME suit. (C) Positions and frequency were determined for five CREs in promoters of above three genes.

CREs not mentioned here might have novel roles in driving cold stress-preferred expression and further experiments will be required to clarify our estimation.

\section{Analysis of GO Enrichment Reveals Biological Processes Associated with Cold Stress Responses in Rice Roots}

To determine the functions of 502 DEGs up-regulated by cold stress in rice roots, we studied their GO terms within the 'biological process' category. In all, 15 terms were highly over-represented in our gene list, with $p$-values $<0.05$ and fold-enrichment values of $>2$-fold (Figure 5 and Supplementary Table S5). We have also previously reported this (Jung et al., 2008b). The terms included 'L-phenylalanine catabolic process' (19.9-fold enrichment), 'response to water' (16.2), 'phenylpropanoid metabolic process' (15.6), 'oxylipin biosynthetic process' (12.9), 'activation of protein kinase C activity by GPCRP signaling pathway' (9.7), 'phospholipid metabolic process' (8.1), 'gibberellin metabolic process' (7.3), 'response to stress' (7.1), 'lipid catabolic process' (6.1), 'protein amino acid dephosphorylation' (5.3), 'trehalose biosynthetic process' (5.2), 'cytochrome complex assembly' (4.7), 'lipid biosynthetic process' (4.4), 'regulation of transcription' (3.2), and 'protein ubiquitination' (3.2).
Of these, 'L-phenylalanine catabolic process' was the most significantly enriched by cold stress while another critical component in that response was 'phenylpropanoid metabolic process.' Transcriptome profile analysis of maize (Zea mays) seedlings in response to cold stress has shown that 31 DEGs for phenylalanine metabolism are induced (Shan et al., 2013). Transcript and metabolic profiling of Arabidopsis thaliana (Charlton et al., 2008) has indicated that phenylpropanoids, along with Lys, Met, Trp, Tyr, Arg, Cys, and the polyamine biosynthetic pathway, are important metabolites that are highly accumulated in response to cold stress. Profiling of maize seedling transcripts by Shan et al. (2013) has also revealed the induction of 54 DEGs for phenylpropanoid metabolism. All of these results suggest that the phenylpropanoid metabolic pathway is activated when various plant species are exposed to cold stress.

Metabolic profiling of Camellia sinensis in response to cold (Wang X.C. et al., 2013) has shown that expression is increased for genes involved in the signal transduction mechanism. Three oxylipin biosynthetic-related genes and two trehalose biosynthetic genes are highly expressed in cold-tolerant Elymus nutans (Fu et al., 2016). Moreover, transcriptomics profiling of Lotus japonicus under cold stress has demonstrated that those conditions lead to the upregulation 


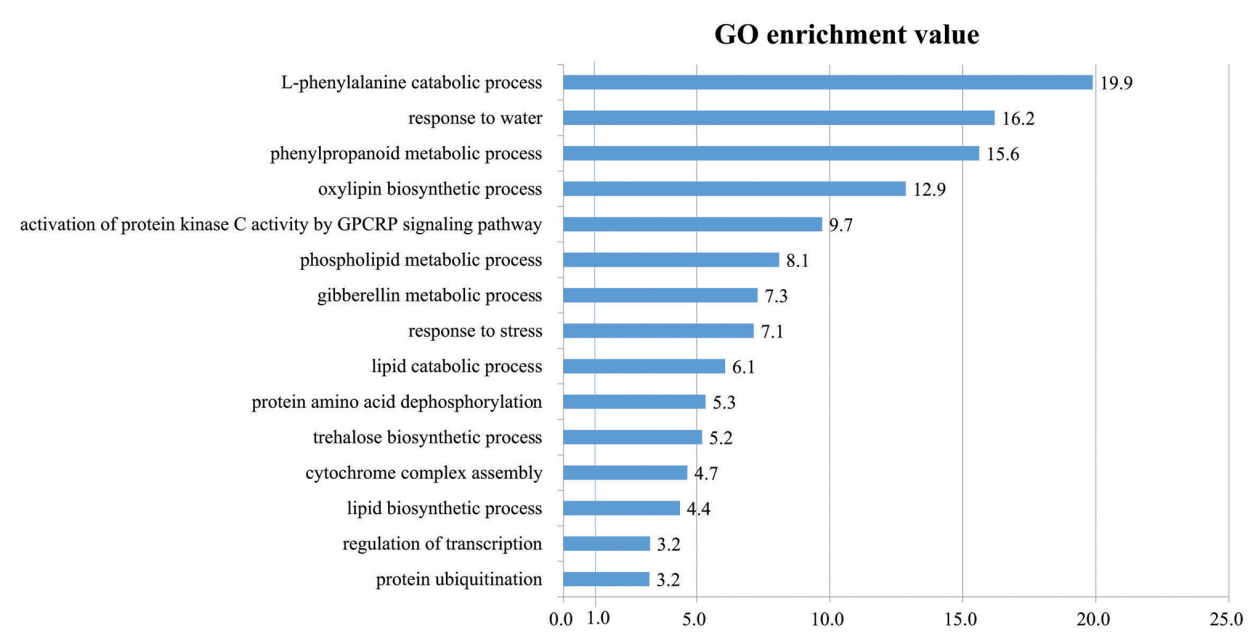

FIGURE 5 | Gene Ontology enrichment analysis in 'Biological Process' category for genes up-regulated in response to cold stress. In all, 15 GO terms were over-represented by $>2$-fold enrichment value, with $p$-values < 0.05. Details of GO assignment are presented in Supplementary Table S4.

of the phospholipid metabolic process (Calzadilla et al., 2016).

Transcriptome profiling has presented the upregulation of GA metabolism in cold-stressed 'Meyer' zoysiagrass (Wei et al., 2015) and greater than threefold induction of gibberellin 2-betadioxygenase genes in cassava, which is also related to responses to abiotic and biotic stimuli (An et al., 2012). All of these reports indicate that the gibberellin metabolic pathway is activated during periods of cold stress.

Genes for 'lipid catabolic process', 'protein amino acid dephosphorylation,' 'cytochrome complex assembly', 'regulation of transcription,' and 'protein ubiquitination' also have important roles in the abiotic-stress response (see, e.g., data in Figure 5). For example, in A. thaliana, several lipid catabolism enzymes in rice (in particular, phospholipids $\mathrm{A}$ and $\mathrm{D}$ ) are activated by low temperatures, as manifested by the heightened accumulation of fatty acids (Wang et al., 2006; Usadel et al., 2008). Serine phosphorylation or dephosphorylation is involved in cold activation signaling of Arabidopsis ICE1, and its Ox in Isatis tinctoria confers cold tolerance (Chinnusamy et al., 2003; Xiang et al., 2013). Campos et al. (2003) have reported that a coldtolerant genotype of Coffea sp. copes with chilling through an enhanced lipid biosynthetic process. Regulation of transcription is also important for cold tolerance. For example, in Arabidopsis, ICE1 and an R2R3-type MYB control the transcriptional regulation of $D R E B$ TFs within the mechanism for cold tolerance (Agarwal et al., 2006; Miura et al., 2007). We also identified 'Protein ubiquitination' as another important GO term that is also linked with cold tolerance. For example, Arabidopsis HOS1 mediates the ubiquitination and degradation of ICE1 and negatively regulates the response to cold stress (Dong et al., 2006). In summary, the biological processes that we identified here as being closely associated with the cold-stress response provide novel and informative resources for improving our knowledge about regulatory factors involved in the molecular mechanism(s) that enable plants to cope in a low-temperature environment.

\section{MapMan Analysis of Cold-Related Genes in Rice Roots}

The MapMan program is very effective for visualizing diverse overviews associated with high-throughput transcriptome data (Jung and An, 2012). We uploaded Locus IDs for 502 DEGs for the cold-stress response (Supplementary Table S3) to various overviews installed in that program. Among them, 79 elements were assigned to the 'RNA' category, 58 to 'protein', 36 to 'signaling,' 25 to 'miscellaneous function' ('misc'), 22 to 'hormone metabolism,' 17 to 'stress,' 14 to 'development,' 13 to 'transport,' 10 each to 'lipid metabolism' and 'cell wall', 7 to 'secondary metabolism,' and a smaller number to other functional groups (Supplementary Table S6). Another 154 genes did not have assigned MapMan terms. In particular, the identification of 17 cold stress-regulated elements supports our proposal that they have potential significance for enhancing tolerance when our candidate genes are expressed.

\section{Analysis of Metabolism Overview Associated with the Cold-Stress Response in Rice}

To investigate the significant metabolic pathways involved in the response to cold stress, we analyzed the Metabolism overview associated with 502 DEGs (Figure 6). Among the 44 elements found there, secondary metabolism included six for phenylpropanoids; nine for lipid metabolism, e.g., phospholipid biosynthesis and lipid degradation; 10 for cell wall metabolism, including cellulose synthase and modification; three for mitochondrial electron transport; seven for major carbohydrate (CHO) metabolism; four for minor CHO metabolism; as well as several others related to this stress, such as amino acid, nitrogen, and nucleotide metabolisms (Figure 6A and Supplementary Table S6). These results implied that a rice plant triggers those metabolic pathways as part of its stress response. Similar to our findings from the GO enrichment analysis, 'L-phenylalanine 


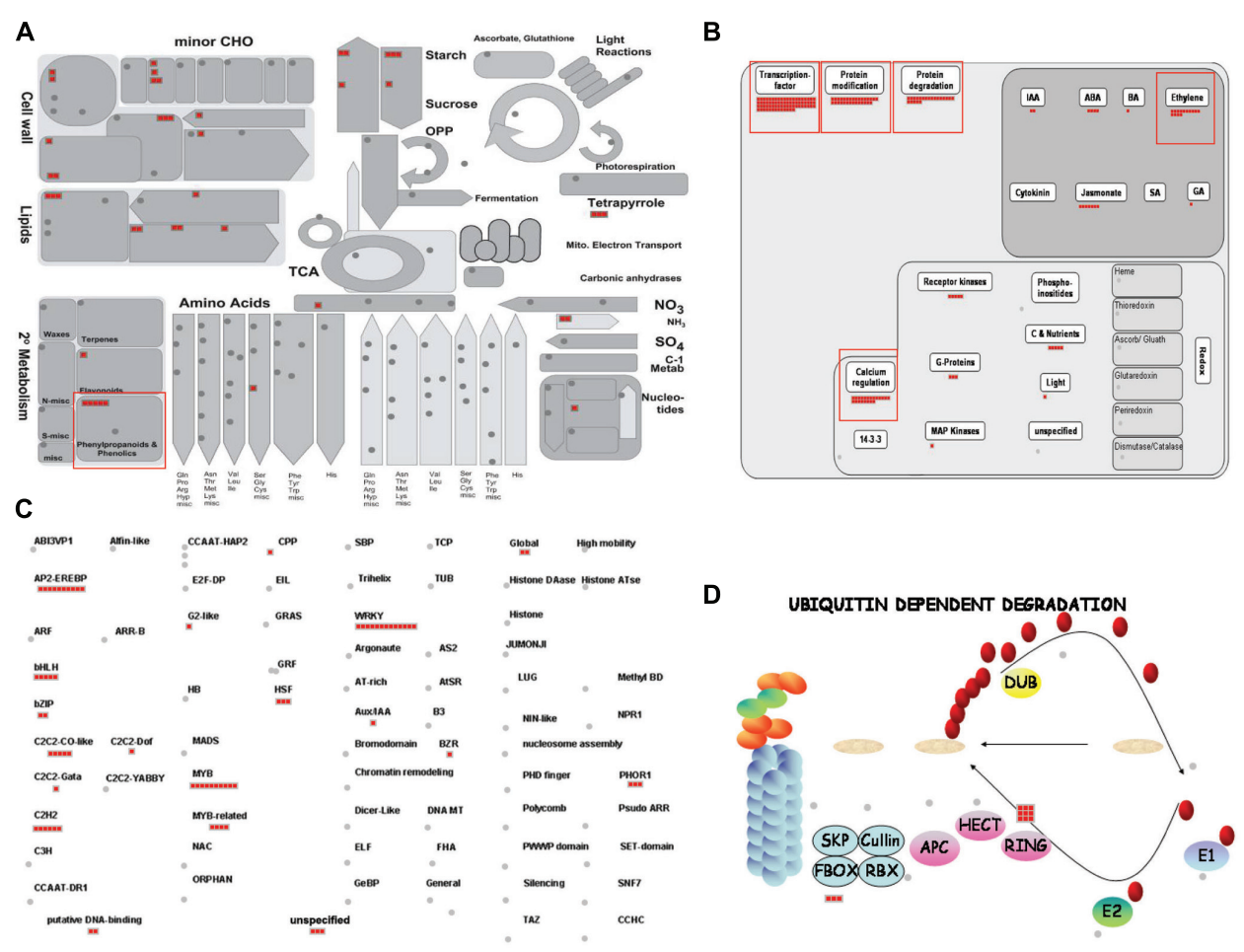

FIGURE 6 | MapMan analysis of rice genes associated with response to cold stress. Overviews of Metabolism (A), Regulation (B), Transcription (C), and Ubiquitin-mediated protein degradation pathway (D) were mapped with selected cold-inducible genes. Red boxes, groups of genes up-regulated by cold stress. Details are presented in Supplementary Table S6.

catabolic process', 'L-phenylalanine metabolic process', and category 'secondary metabolism' (including 'phenylpropanoid metabolism') were over-represented.

\section{Analyses of Regulation, Transcription, and Ubiquitin-Dependent Proteasome Pathway Overviews Associated with the Cold-Stress Response in Rice}

Our Regulation overview of 502 DEGs demonstrated that 73 TFs, 30 genes related to protein modification, 21 associated with protein degradation, and 22 related to hormone metabolism were up-regulated in rice during periods of cold stress (Figure 6B). Of these, the TFs were the most abundant, meaning that they are largely involved in regulating the response and tolerance of rice to such conditions. Therefore, those genes should be considered candidates for further study to regulate the cold-stress response in rice. Accordingly, we found $13 \mathrm{WRKY}$ TFs, $10 \mathrm{MYB}$ and four MYB-related TFs, 10 Apetala2/Ethylene Responsive Element Binding Proteins (AP2/EREBPs), five Basic Helix-Loop-Helix (bHLH) genes, five Constans (CO)-like zinc finger family TFs, five $\mathrm{C} 2 \mathrm{H} 2$ zinc finger family TFs, and other TFs for this response (Figure 6C and Supplementary Table S6).

In plants, the WRKY TFs have been more actively studied than others, and most of them have positive roles in the cold-stress response in various plant species, including Ipomoea batatas, where the function of a WRKY TF was first described (Ishiguro and Nakamura, 1994). This TF contains a WYRKY domain and a zinc-finger motif. Marè et al. (2004) have reported the role of $H v$-WRKY38 in the cold-stress response by Hordeum vulgare, and Ox of WYRKY76 and WYRKY71 has been shown to increase cold tolerance in rice (Yokotani et al., 2013; Kim et al., 2016). Likewise, Ox of CsWYRKY46 in Cucumis sativus regulates tolerance to chilling and freezing (Zhang et al., 2016), and the cold-inducible BcWYRKY46 from Brassica campestris enhances cold tolerance in transgenic tobacco (Nicotiana tabacum) (Wang et al., 2012). In contrast, OsWYRKY45 and OsWRKY13 negatively regulate cold tolerance in rice (Qiu et al., 2008; Tao et al., 2011), while WYRKY34 mediates the cold sensitivity of mature pollen in A. thaliana (Zou et al., 2010). CsWRKY2, a novel WRKY gene from Camellia sinensis, is involved in cold stress responses (Wang Y. et al., 2016).

Like WRKY TFs, MYB TFs have important roles in cold tolerance. They include OsMYB4 OsMYB2 and MYBS3 in rice (Vannini et al., 2004; Su et al., 2010; Yang et al., 2012), MYB15 and HOS10 in Arabidopsis (Zhu et al., 2005; Agarwal et al., 2006), and GmMYBj1 in soybean (Su et al., 2014); and TaMYB3R1 in Triticum aestivum (Cai et al., 2015). Whereas all of those TFs have positive effects, $M Y B C 1$ in Arabidopsis negatively regulates cold tolerance (Zhai et al., 2010).

The AP2/EREBP TFs also enhance cold tolerance. They include JcDREB, JcCBF2, BnaERF-B3-hy15, DEAR1, ZmDREB1A, OsDREB1D, and ZmDBP4 analyzed in Arabidopsis (Qin et al., 2004; Tsutsui et al., 2009; Zhang et al., 2009; Wang et al., 2010, 
2014; Tang et al., 2011; Xiong et al., 2013); and JERF1, OsDREB1, and AtDREB1A in tobacco (Kasuga et al., 2004; Li et al., 2005; Wu et al., 2007).

A major TF family of other TFs involved in cold tolerance is bHLH. ICE1, ICE2, VabHLH1, and OrbHLH0O1 analyzed in Arabidopsis (Chinnusamy et al., 2003; Fursova et al., 2009; Li et al., 2010; Xu et al., 2014) and OsbHLH1 in rice (Wang et al., 2003) are involved in cold tolerance. Next, HOS1, a member of the CO-like zinc finger family, regulates cold tolerance in Arabidopsis via CONSTANS degradation (Jung et al., 2012), while OsZFP245, a member of the C2H2 zinc finger family, confers such tolerance in rice (Huang et al., 2009).

Related to protein degradation, signal transduction, and hormone metabolism, a few studies have been conducted. Therefore, future analyses of uncharacterized TFs and the regulatory elements associated with protein degradation, signal transduction, and hormone metabolism identified in this study might shed the light on the effective methods for improving cold tolerance in rice.

\section{Evaluation of Candidate Genes Associated with Cold Stress Using Rice Genes with Known Functions}

To evaluate the significance of our candidate genes, we searched the literature to determine if functions for them have been reported previously. This was accomplished with the online OGRO database, which provides a thorough summary of rice genes that have been characterized through molecular and genetic techniques (Yamamoto et al., 2012). That summary presents the roles of 49 genes according to three agronomic trait categories: morphological, physiological, and resistance/tolerance. The functional identification of genes related to resistance/tolerance traits is the most abundant, with 27 genes being part of that category, including 12 genes involved in cold tolerance; 16, drought tolerance; 11 , salinity tolerance; six, blast resistance; five, bacterial blight resistance; two, soil stress tolerance; one each for sheath blight resistance and insect resistance; and four for other stress resistances (Figure 7). Of these, 17 genes are partially responsible for at least two traits in that resistance/tolerance category. OsMAPK5 and OsWRKY45 are involved in tolerance to both biotic stress (bacterial blight and blast) and abiotic stress (drought, salinity, and cold). Others include OsMYB2, ZFP182, OsDREB1A, OsDREB1B, and OsDREB1C, for responses to drought, salinity, and cold; OsbZIP52/RISBZ5 and OsCAF1B, cold and drought; OsTPP1, cold and salinity; and OsCPK4, OsCDPK7, and OsNAC045, drought and salinity. The results from our transcriptome analysis had also suggested that these last three are active in the cold-stress response. We found it interesting that genes induced by low temperatures also function in other abioticstress responses. This implies that regulation of those responses is very complex and that intensive crosstalk might occur among them.

Regarding morphological traits, 13 genes are related to dwarfism, five to rooting, four to culms/leaves, three to seeds, three to shoots/seedlings, two to panicles/flowers, and three to other plant components (Figure 7). These results indicate that the cold stress-responsive genes studied here might also affect various traits, e.g., dwarfism, that can inhibit or delay normal growth. Regarding physiological traits, we found that two genes each are related to flowering, germination dormancy, and source activity, while one is related to sterility, and one to other traits (Figure 7). Because our findings demonstrate an interaction between cold stress and diverse morphological/physiological traits, we suggest that future studies should screen mutants and focus on their morphological and physiological phenotypes while also screening phenotypes under cold-stress conditions.

\section{Evaluating the Functional Significance of Cold-Inducible Genes Using a Gain-of-Function Mutant for OsWRKY71}

Among the cold-inducible genes identified in our study, OsWRKY71 is induced by cold stress(Figure 1F). As we have reported previously(Kim et al., 2016), its Ox leads to cold tolerance(Figure 8). The survival rate is $19 \%$ higherfor OsWRKY71-Ox lines than for the WT, and the transgenics also have $30 \%$ higher FWs and $60 \%$ higher DWs. Estimating $F_{\mathrm{v}} / F_{\mathrm{m}}$ values is a good way to depict photosynthetic efficiency under cold stress. Our data indicated that, after $96 \mathrm{~h}$ of chilling treatment, this efficiency in OsWRKY71-Ox lines decreased from 0.8 to 0.5 while that value in the WT declined from 0.8 to 0.3 . Therefore, the Ox lines are 25\% more efficient and OsWRKY71 confers cold tolerance.

\section{Hypothetical Model for Regulating the Cold-Stress Response that Is Conserved between japonica and indica Rice Cultivars}

The response to low temperatures can be divided into four steps: perception of cold stress, signaling cascades for the response, regulation of gene expression, and protection from freezing damage. Our proposed model (Figure 9) is based on published physiological and biochemical aspects as well as reports of functions for genes involved in the relevant signaling and transcriptional pathways.

We theorize that the first reaction by a plant to chilling is to increase membrane rigidity. This is followed by the generation of ROS, then regulation of phosphate homeostasis and activation of calcium receptors and histidine kinases. The ensuing signal transduction cascades are coupled with signal perception. Examples include MAP kinase cascades and a two-component signaling system by histidine kinase. The former is more likely because the cascades of MAP kinase (OsMAPK5/LOC_Os03g17700.1), MAP kinase kinase (MAP2K; OsMKK4/LOC_Os02g54600.1), and MAP kinase kinase kinase (MAP3K, seven members in Figure 9), are stimulated in response to cold stress, making them the most probable candidates for this pathway. Of them, it has been known that OsMAPK5 positively regulates tolerance to cold temperatures and other sources of stress (Xiong and Yang, 2003).

For the latter possibility, the processes might be more complex. In response to cold, plants use $\mathrm{Ca}^{2+}$ as a signal. Although we did not yet identify the histidine kinase genes 


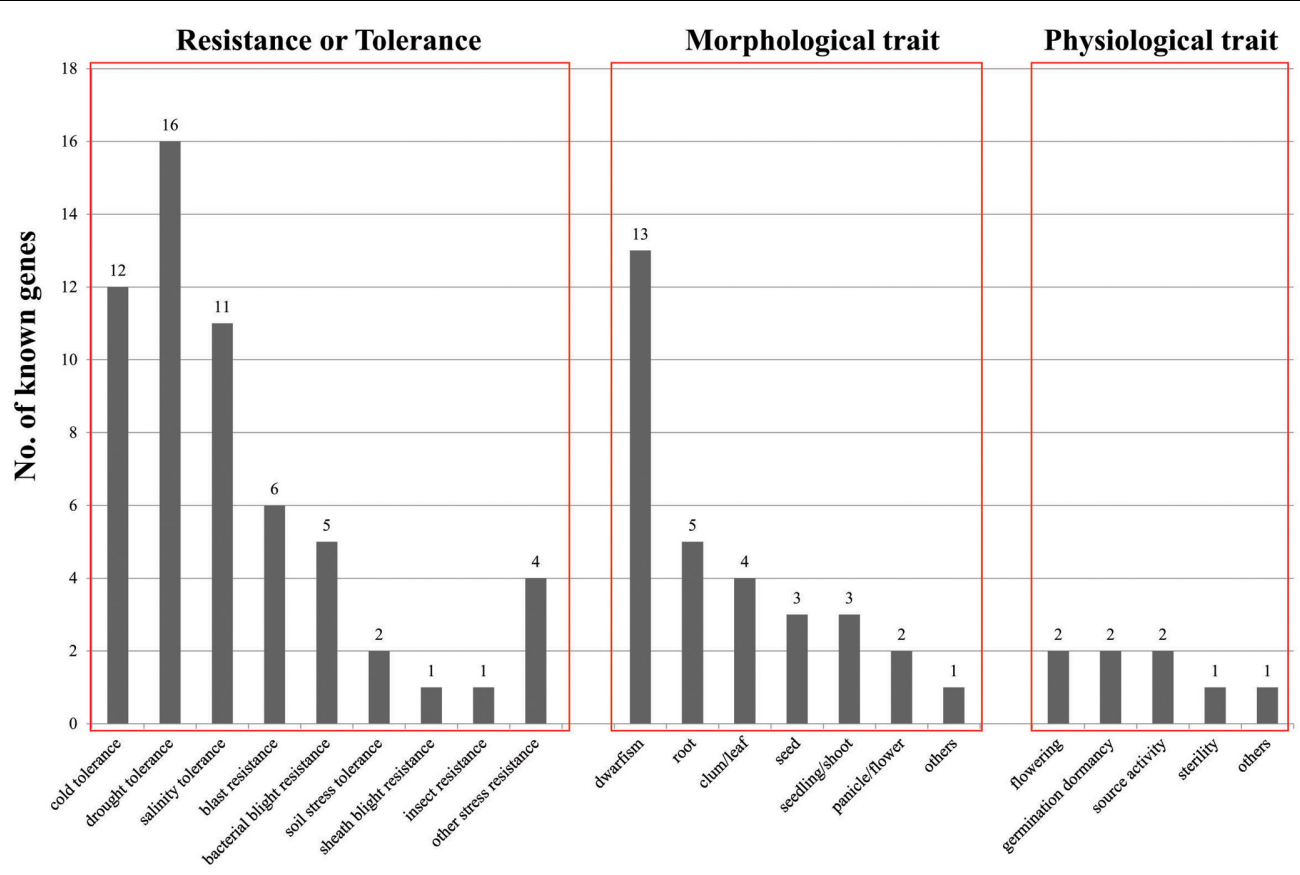

FIGURE 7 | Distribution of functionally characterized genes according to three major agronomic categories. $Y$-axis, number of known genes; $X$-axis, minor functional categories in three major functional categories, presented in order of "Resistance or Tolerance," "Morphological trait," and "Physiological trait".

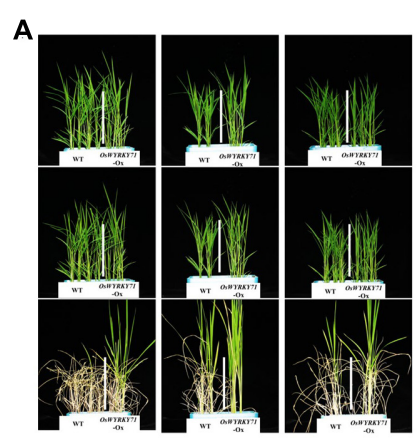

B

\begin{tabular}{|c|c|c|}
\hline Cold Stress $\left(4^{\circ} \mathrm{C}\right) 5 \mathrm{~d}$ & WT & OsWYRKY71-0x \\
\hline Plant survival & $\begin{array}{c}38 / 114 \\
33 \%\end{array}$ & $\begin{array}{c}46 / 88^{*} \\
52 \%\end{array}$ \\
\hline
\end{tabular}

\section{C}

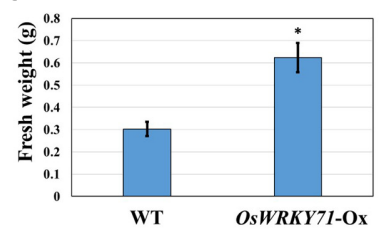

D

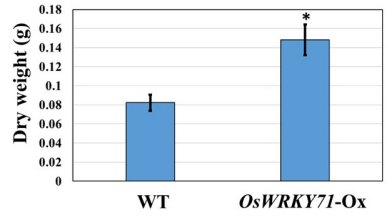

E
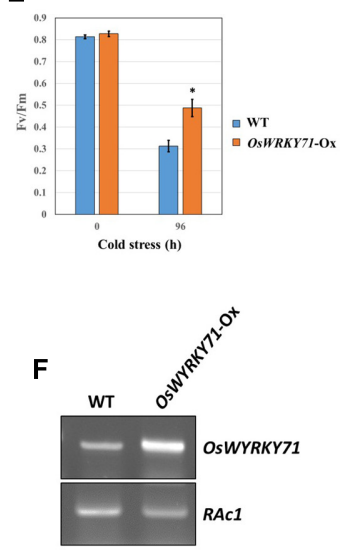

FIGURE 8 | Cold-stress response mediated by OsWYRKY71 using Ox line. (A) Phenotype of response by OsWYRKY71-Ox line observed after 10-DAG rice seedlings were exposed to cold treatment for 5 days, followed by 6 days of recovery. (B) Cold tolerance of OsWYRKY71-Ox line, based on survival rates. (C) Fresh weights of OsWYRKY71-Ox line compared with WT after recovery. (D) Dry weights of OsWYRKY71-Ox line compared with WT after recovery. (E) $F_{\mathrm{v}} / F_{\mathrm{m}}$ rates compared between OsWYRKY71-Ox line and WT during cold-stress period. (F) RT-PCR results for OsWYRKY71-Ox line and we used RAc1 as an internal control. $*, 0.01<p$-value $<0.05$.

in rice showing significant induction under cold stress, the signal received by a $\mathrm{Ca}^{2+}$ channel might bind to a $\mathrm{Ca}^{2+}$ sensor, such as calmodulin ( $\mathrm{CaM})$, and CaM-like protein might stimulate $\mathrm{Ca}^{2+} / \mathrm{CaM}$-dependent protein kinases as suggested in Figure 9. Thereafter, gene expression is regulated by TFs through a process that incorporates $\mathrm{CBF} / \mathrm{DREB}$-dependent or -independent pathways.
In the case of the CBF/DREB-dependent pathway, a signal from the map kinase cascades is recognized by ICE1, which encodes a bHLH TF that activates the expression of DREB genes in the downstream pathway by directly binding the promoter regions. This results in stimulation of cold stress-responsive genes that are required for altering cellular metabolism. OsbHLH148 or RERJ1 are probable candidate genes, having the same roles 


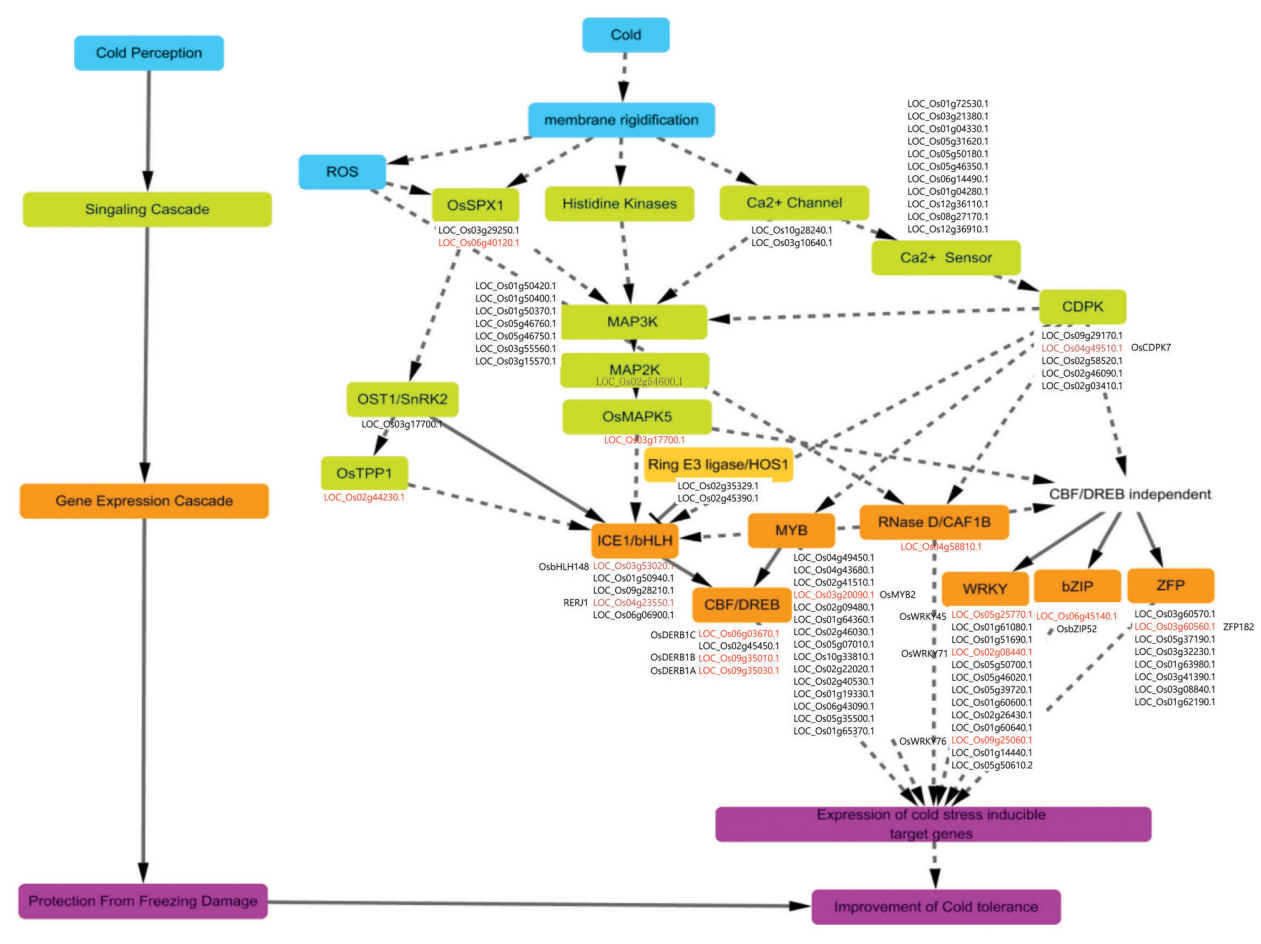

FIGURE 9 | Overview of regulatory pathway for cold-stress signaling in rice. Signaling and transcriptional regulatory pathways for cold tolerance have four steps: cold perception (blue boxes), signaling cascades (green boxes), gene expression cascades (brown boxes)/protein degradation (light-brown boxes), and protection from cold (tolerance) through activation of target genes (pink boxes). Cold-inducible candidate genes were mapped to individual boxes and are presented as locus IDs. Red-colored locus IDs are genes previously characterized for cold-stress responses, with each name indicated either on left side or below corresponding ID. Brown-colored locus IDs are genes previously characterized but not directly linked with cold-stress response.

as ICE1 in Arabidopsis, i.e., OsbHLH148 is involved in drought tolerance and RERJ1 functions in normal plant growth and development (Seo et al., 2011). OsDREB1A, OsDREB1B, and OsDREB1C have roles in tolerance to cold, drought, and salinity by triggering the expression of target genes (Ito et al., 2006). Regarding the CRT/DREB-independent pathway, TFs such as OsWRKY71 (Kim et al., 2016), OsWRKY76 (Yokotani et al., 2013), OsbZIP52 (Liu et al., 2012), ZFP182 (Huang et al., 2012), and OsMYB2 (Yang et al., 2012) are components of the trait for cold stress response. For example, a rice line that over-expressor of OsbZIP52 displays a cold-sensitive phenotype (Liu et al., 2012) and the application of such stress induces the expression of OsbZIP52, which then negatively affects the extent of that tolerance.

Although the functions of most genes for cold tolerance have not yet been defined, other types of TFs identified in our metaexpression and MapMan analyses might also be important for regulating tolerance, as indicated by the TF overview presented by MapMan (Figure 6 and Supplementary Table S6).

Among other processes, HOS1, encoding the ring type E3 ligase, participates in the degradation process of ICE1 that is stimulated at low temperature, resulting in inactivation of the CRT/DREB-dependent transcription regulation pathway (Chinnusamy et al., 2003; Dong et al., 2006). Likewise, OST1, encoding the well-known Ser /Thr protein kinase, is activated in response to cold and phosphorylates ICE1, leading to its stability and transcriptional activity (Ding et al., 2015). However, OST1 also hinders the interaction between HOS1 and ICE1, subsequently leading to the degradation of ICE1 under cold stress when HOS1 is suppressed. OsCAF1B, with RNase D activity, functions in post-transcriptional regulation and may affect various pathways for cold tolerance (Chou et al., 2014). OsTPP1 has a role in resistance to abiotic stress. At low temperatures, it also positively regulates the expression of tolerance genes by participating in the glucose deprivation signaling pathway (Ge et al., 2008). Despite these numerous reports, however, all of these hypotheses must still be verified through further experiments.

Cold stress is one of the main environmental factors that adversely affect plant growth and yield. Thus, it is important that we understand this stress signaling and its regulatory network if we are to develop cultivars with greater tolerance. To this end, we have produced a hypothetical model that considers our current findings as well as data derived from earlier research.

\section{CONCLUSION}

Our study goal was to identify low-temperature-responsive genes that can be commonly used by rice researchers throughout the world. For this, we collected a broad range of genome-wide transcriptome data produced from plants under low-temperature conditions. This information included data deposited from 
published microarrays or re-processed from RNA-seq analyses. The 502 genes identified here are conserved between japonica and indica cultivars, two representative subspecies of rice. Results of bioinformatics analyses using GO enrichment and MapMan tools for these candidate genes was applied to reveal important biological processes and related metabolic and regulatory pathways. In addition, we constructed a possible regulatory network based on such information. Serving as a valuable foundation for future research, our proposed model can help in the discovery of key regulatory genes that confer cold tolerance. This can be accomplished by using a gene-indexed mutant collection or biotechnological approaches that are wellestablished in rice.

\section{AUTHOR CONTRIBUTIONS}

K-HJ, MK, and S-RK design overall experimental schemes. MK and Y-SG performed experiments. MK and K-HJ wrote manuscript.

\section{REFERENCES}

Abe, N., Asai, H., Yago, H., Oitome, N. F., Itoh, R., Crofts, N., et al. (2014). Relationships between starch synthase I and branching enzyme isozymes determined using double mutant rice lines. BMC Plant Biol. 14:80. doi: 10.1186/ 1471-2229-14-80

Agarwal, M., Hao, Y., Kapoor, A., Dong, C.-H., Fujii, H., Zheng, X., et al. (2006). A R2R3 type MYB transcription factor is involved in the cold regulation of CBF genes and in acquired freezing tolerance. J. Biol. Chem. 281, 37636-37645. doi: 10.1074/jbc.M605895200

An, D., Yang, J., and Zhang, P. (2012). Transcriptome profiling of low temperaturetreated cassava apical shoots showed dynamic responses of tropical plant to cold stress. BMC Genomics 13:64. doi: 10.1186/1471-2164-13-64

Asahina, M., Tamaki, Y., Sakamoto, T., Shibata, K., Nomura, T., and Yokota, T. (2014). Blue light-promoted rice leaf bending and unrolling are due to upregulated brassinosteroid biosynthesis genes accompanied by accumulation of castasterone. Phytochemistry 104, 21-29. doi: 10.1016/j.phytochem.2014.04.017

Aya, K., Hobo, T., Sato-Izawa, K., Ueguchi-Tanaka, M., Kitano, H., and Matsuoka, M. (2014). A novel AP2-type transcription factor, SMALL ORGAN SIZE1, controls organ size downstream of an auxin signaling pathway. Plant Cell Physiol. 55, 897-912. doi: 10.1093/pcp/pcu023

Bai, M. Y., Zhang, L. Y., Gampala, S. S., Zhu, S. W., Song, W. Y., Chong, K., et al. (2007). Functions of OsBZR1 and 14-3-3 proteins in brassinosteroid signaling in rice. Proc. Natl. Acad. Sci. U.S.A. 104, 13839-13844. doi: 10.1073/ pnas.0706386104

Bailey, T. L., Williams, N., Misleh, C., and Li, W. W. (2006). MEME: discovering and analyzing DNA and protein sequence motifs. Nucleic Acids Res. 34, W369-W373. doi: 10.1093/nar/gkl198

Barrett, T., Troup, D. B., Wilhite, S. E., Ledoux, P., Evangelista, C., Kim, I. F., et al. (2011). NCBI GEO: archive for functional genomics data sets-10 years on. Nucleic Acids Res. 39, D1005-D1010. doi: 10.1093/nar/gkq1184

Busk, P. K., and Pagès, M. (1998). Regulation of abscisic acid-induced transcription. Plant Mol. Biol. 37, 425-435. doi: 10.1023/A:1006058700720

Cai, X., Cai, M., and Lou, L. (2015). Identification of differentially expressed genes and small molecule drugs for the treatment of tendinopathy using microarray analysis. Mol Med Rep. 11, 3047-3054. doi: 10.1016/j.gene.2014.12.066

Calzadilla, P. I., Maiale, S. J., Ruiz, O. A., and Escaray, F. J. (2016). Transcriptome response mediated by cold stress in Lotus japonicas. Front. Plant. Sci. 7:374. doi: 10.3389/fpls.2016.00374

Campo, S., Baldrich, P., Messeguer, J., Lalanne, E., Coca, M., and San Segundo, B. (2014). Overexpression of a calcium-dependent protein kinase confers salt and drought tolerance in rice by preventing membrane lipid peroxidation. Plant Physiol. 165, 688-704. doi: 10.1104/pp.113.230268

\section{ACKNOWLEDGMENTS}

This work was supported by grants from the NextGeneration BioGreen 21 Program PJ01192701 to S-RK and Basic Science Research Program through the National Research Foundation of Korea (NRF) funded by the Ministry of Education (NRF-2016R1D1A1A09919568 to $\mathrm{K}-\mathrm{HJ}$, the Rural Development Administration, Republic of Korea.

\section{SUPPLEMENTARY MATERIAL}

The Supplementary Material for this article can be found online at: http://journal.frontiersin.org/article/10.3389/fpls.2017.01120/ full\#supplementary-material

FIGURE S1 | Validation of expression patterns for three genes (LOC_Os03g49830, LOC_Os10g41200, and LOC_Os01g31370) under cold stress using qRT-PCR analysis. ${ }^{* * *}, p$-value $<0.001$.

Campos, P. S., Quartin, V., Ramalho, J. C., and Nunes, M. A. (2003). Electrolyte leakage and lipid degradation account for cold sensitivity in leaves of Coffea sp. plants. J. Plant Physiol. 160, 283-292. doi: 10.1078/0176-161700833

Cao, P., Jung, K. H., Choi, D., Hwang, D., Zhu, J., and Ronald, P. C. (2012). The rice oligonucleotide array database: an atlas of rice gene expression. Rice (NY) 5, 17. doi: 10.1186/1939-8433-5-17

Chang, W. C., Lee, T. Y., Huang, H. D., Huang, H. Y., and Pan, R. L. (2008). PlantPAN: plant promoter analysis navigator, for identifying combinatorial cis-regulatory elements with distance constraint in plant gene groups. BMC Genomics 9:561. doi: 10.1186/1471-2164-9-561

Charlton, A. J., Donarski, J. A., Harrison, M., Jones, S. A., Godward, J., Oehlschlager, S., et al. (2008). Responses of the pea (Pisum sativum L.) leaf metabolome to drought stress assessed by nuclear magnetic resonance spectroscopy. Metabolomics 4, 312-327. doi: 10.1007/s11306-008-0128-0

Chawade, A., Lindlöf, A., Olsson, B., and Olsson, O. (2013). Global expression profiling of low temperature induced genes in the chilling tolerant japonica rice Jumli Marshi. PLoS ONE 8:e81729. doi: 10.1371/journal.pone.00 81729

Chinnusamy, V., Ohta, M., Kanrar, S., Lee, B. H., Hong, X., Agarwal, M., et al. (2003). ICE1: a regulator of cold-induced transcriptome and freezing tolerance in Arabidopsis. Genes Dev. 17, 1043-1054. doi: 10.1101/gad.1077503

Chou, W. L., Huang, L. F., Fang, J. C., Yeh, C. H., Hong, C. Y., Wu, S. J., et al. (2014). Divergence of the expression and subcellular localization of CCR4associated factor 1 (CAF1) deadenylase proteins in Oryza sativa. Plant Mol. Biol. 85, 443-458. doi: 10.1007/s11103-014-0196-7

Chow, C. N., Zheng, H. Q., Wu, N. Y., Chien, C. H., Huang, H. D., Lee, T. Y., et al. (2016). PlantPAN 2.0: an update of plant promoter analysis navigator for reconstructing transcriptional regulatory networks in plants. Nucleic Acids Res. 44, D1154-D1160. doi: 10.1093/nar/gkv1035

Chu, V. T., Gottardo, R., Raftery, A. E., Bumgarner, R. E., and Yeung, K. Y. (2008). $\mathrm{MeV}+\mathrm{R}$ : using $\mathrm{MeV}$ as a graphical user interface for Bioconductor applications in microarray analysis. Genome Biol. 9:R118. doi: 10.1186/gb-2008-9-7r118

Ding, Y., Li, H., Zhang, X., Xie, Q., Gong, Z., and Yang, S. (2015). OST1 kinase modulates freezing tolerance by enhancing ICE1 stability in Arabidopsis. Dev. Cell 32, 278-289. doi: 10.1016/j.devcel.2014.12.023

Dong, C. H., Agarwal, M., Zhang, Y., Xie, Q., and Zhu, J. K. (2006). The negative regulator of plant cold responses, HOS1, is a RING E3 ligase that mediates the ubiquitination and degradation of ICE1. Proc. Natl. Acad. Sci. U.S.A. 103, 8281-8286. doi: 10.1073/pnas.0602874103

Dubouzet, J. G., Sakuma, Y., Ito, Y., Kasuga, M., Dubouzet, E. G., Miura, S., et al. (2003). OsDREB genes in rice, Oryza sativa L., encode transcription activators 
that function in drought-, high-salt- and cold-responsive gene expression. Plant J. 33, 751-763. doi: 10.1046/j.1365-313X.2003.01661.x

Frey, N., Klotz, J., and Nick, P. (2010). A kinesin with calponin-homology domain is involved in premitotic nuclear migration. J. Exp. Bot. 61, 3423-3437. doi: $10.1093 / \mathrm{jxb} / \mathrm{erq} 164$

Fu, J., Miao, Y., Shao, L., Hu, T., and Yang, P. (2016). De novo transcriptome sequencing and gene expression profiling of Elymus nutans under cold stress. BMC Genomics 17:870. doi: 10.1186/s12864-016$3222-0$

Fursova, O. V., Pogorelko, G. V., and Tarasov, V. A. (2009). Identification of ICE2, a gene involved in cold acclimation which determines freezing tolerance in Arabidopsis thaliana. Gene 429, 98-103. doi: 10.1016/j.gene.2008.10.016

Ge, L. F., Chao, D. Y., Shi, M., Zhu, M. Z., Gao, J. P., and Lin, H. X. (2008). Overexpression of the trehalose-6-phosphate phosphatase gene OsTPP1 confers stress tolerance in rice and results in the activation of stress responsive genes. Planta 228, 191-201. doi: 10.1007/s00425-008-0729-x

Hakata, M., Kuroda, M., Ohsumi, A., Hirose, T., Nakamura, H., Muramatsu, M., et al. (2012). Overexpression of a rice TIFY gene increases grain size through enhanced accumulation of carbohydrates in the stem. Biosci. Biotechnol. Biochem. 76, 2129-2134. doi: 10.1271/bbb.120545

Han, M., Kim, C. Y., Lee, J., Lee, S. K., and Jeon, J. S. (2014). OsWRKY42 represses OsMT1d and induces reactive oxygen species and leaf senescence in rice. Mol. Cells 37, 532-539. doi: 10.14348/molcells.2014.0128

Hong, W. J., Yoo, Y. H., Park, S. A., Moon, S., Kim, S. R., An, G., et al. (2017). Genome-wide identification and extensive analysis of rice-endosperm preferred genes using reference expression database. J. Plant Biol. 60, 249-258. doi: $10.1007 / \mathrm{s} 12374-016-0552-\mathrm{z}$

Huang, J., Sun, S., Xu, D., Lan, H., Sun, H., Wang, Z., et al. (2012). A TFIIIAtype zinc finger protein confers multiple abiotic stress tolerances in transgenic rice (Oryza sativa L.). Plant Mol. Biol. 80, 337-350. doi: 10.1007/s11103-0129955-5

Huang, J., Sun, S. J., Xu, D. Q., Yang, X., Bao, Y. M., Wang, Z. F., et al. (2009). Increased tolerance of rice to cold, drought and oxidative stresses mediated by the overexpression of a gene that encodes the zinc finger protein ZFP245. Biochem. Biophys. Res. Commun. 389, 556-561. doi: 10.1016/j.bbrc.2009.09.032

Huang, J., Yang, X., Wang, M. M., Tang, H. J., Ding, L. Y., Shen, Y., et al. (2007). A novel rice $\mathrm{C} 2 \mathrm{H} 2$-type zinc finger protein lacking DLN-box/EAR-motif plays a role in salt tolerance. Biochim. Biophys. Acta 1769, 220-227. doi: 10.1016/j. bbaexp.2007.02.006

Ishiguro, S., and Nakamura, K. (1994). Characterization of a cDNA encoding a novel DNA-binding protein, SPF1, that recognizes SP8 sequences in the 5' upstream regions of genes coding for sporamin and $\beta$-amylase from sweet potato. Mol. Gen. Genet. 244, 563-571. doi: 10.1007/BF00282746

Ito, Y., Katsura, K., Maruyama, K., Taji, T., Kobayashi, M., Seki, M., et al. (2006). Functional analysis of rice DREB1/CBF-type transcription factors involved in cold-responsive gene expression in transgenic rice. Plant Cell Physiol. 47, 141-153. doi: $10.1093 / \mathrm{pcp} / \mathrm{pci} 230$

Iwamoto, M., Higo, K., and Takano, M. (2009). Circadian clock- and phytochromeregulated Dof-like gene, Rdd1, is associated with grain size in rice. Plant Cell Environ. 3, 592-603. doi: 10.1111/j.1365-3040.2009.01954.x

Jeong, H. J., and Jung, K. H. (2015). Rice tissue-specific promoters and conditiondependent promoters for effective translational application. J. Integr. Plant Biol. 57, 913-924. doi: 10.1111/jipb.12362

Jung, J. H., Seo, P. J., and Park, C. M. (2012). The E3 ubiquitin ligase HOS1 regulates Arabidopsis flowering by mediating CONSTANS degradation under cold stress. J. Biol. Chem. 287, 43277-43287. doi: 10.1074/jbc.M112.394338

Jung, K. H., and An, G. (2012). Application of MapMan and RiceNet drives systematic analyses of the early heat stress transcriptome in rice seedlings. J. Plant Biol. 55, 436-449. doi: 10.1007/s12374-012-0270-0

Jung, K. H., An, G., and Ronald, P. C. (2008b). Towards a better bowl of rice: assigning function to tens of thousands of rice genes. Nat. Rev. Genet. 9, 91-101. doi: $10.1038 / \mathrm{nrg} 2286$

Jung, K. H., Dardick, C., Bartley, L. E., Cao, P., Phetsom, J., Canlas, P., et al. (2008a). Refinement of light-responsive transcript lists using rice oligonucleotide arrays: evaluation of gene-redundancy. PLoS ONE 3:e3337. doi: 10.1371/journal.pone. 0003337

Jung, K. H., Han, M. J., Lee, D. Y., Lee, Y. S., Schreiber, L., Franke, R., et al. (2006). Wax-deficient antherl is involved in cuticle and wax production in rice anther walls and is required for pollen development. Plant Cell 18, 3015-3032. doi: 10.1105/tpc.106.042044

Jung, K. H., Han, M. J., Lee, Y. S., Kim, Y. W., Hwang, I., Kim, M. J., et al. (2005). Rice Undeveloped Tapetum 1 is a major regulator of early tapetum development. Plant Cell 17, 2705-2722. doi: 10.1105/tpc.105.034090

Jung, K. H., Kim, S. R., Giong, H. K., Nguyen, M. X., Koh, H. J., and An, G. (2015). Genome-wide identification and functional analysis of genes expressed ubiquitously in rice. Mol. Plant 8, 276-289. doi: 10.1016/j.molp.2014.10.013

Kaneda, T., Taga, Y., Takai, R., Iwano, M., Matsui, H., Takayama, S., et al. (2009). The transcription factor OsNAC4 is a key positive regulator of plant hypersensitive cell death. EMBO J. 28, 926-936. doi: 10.1038/emboj. 2009.39

Kasuga, M., Miura, S., Shinozaki, K., and Yamaguchi-Shinozaki, K. (2004). A combination of the Arabidopsis DREB1A gene and stress-inducible rd29A promoter improved drought- and low-temperature stress tolerance in tobacco by gene transfer. Plant Cell Physiol. 45, 346. doi: 10.1093/pcp/pch037

Kim, C. Y., Vo, K. T. X., Nguyen, C. D., Jeong, D. H., Lee, S. K., Kumar, M., et al. (2016). Functional analysis of a cold-responsive rice WRKY gene, OsWRKY71. Plant Biotechnol. Rep. 10, 13-23. doi: 10.1007/s11816-015-0383-2

Kiribuchi, K., Sugimori, M., Takeda, M., Otani, T., Okada, K., Onodera, H., et al. (2004). RERJ1, a jasmonic acid-responsive gene from rice, encodes a basic helix-loop-helix protein. Biochem. Biophys. Res. Commun. 325, 857-863. doi: $10.1016 /$ j.bbrc.2004.10.126

Koiwai, H., Tagiri, A., Katoh, S., Katoh, E., Ichikawa, H., Minami, E., et al. (2007). RING-H2 type ubiquitin ligase EL5 is involved in root development through the maintenance of cell viability in rice. Plant J. 51, 92-104. doi: 10.1111/j.1365313X.2007.03120.x

Kudo, T., Makita, N., Kojima, M., Tokunaga, H., and Sakakibara, H. (2012). Cytokinin activity of cis-zeatin and phenotypic alterations induced by overexpression of putative cis-zeatin-O-glucosyltransferase in rice. Plant Physiol. 160, 319-331. doi: 10.1104/pp.112.196733

Kumar, M., Choi, J., An, G., and Kim, S.-R. (2017). Ectopic expression of OsSta2 enhances salt stress tolerance in rice. Front. Plant Sci. 8:316. doi: 10.3389/fpls. 2017.00316

Kumar, M., Lee, S. C., Kim, J. Y., Kim, S. J., Aye, S. S., and Kim, S. R. (2014). Over-expression of dehydrin gene, OsDhn1, improves drought and salt stress tolerance through scavenging of reactive oxygen species in rice (Oryza sativa L.). J. Plant Biol. 57, 383-393. doi: 10.1007/s12374-014-0487-1

Kwon, Y. I., Abe, K., Osakabe, K., Endo, M., Nishizawa-Yokoi, A., Saika, H., et al. (2012). Overexpression of OsRecQl4 and/or OsExo1 enhances DSBinduced homologous recombination in rice. Plant Cell Physiol. 53, 2142-2152. doi: $10.1093 / \mathrm{pcp} / \mathrm{pcs} 155$

Lee, S.-C., Kim, J.-Y., Kim, S.-H., Kim, S.-J., Lee, K., Han, S.-K., et al. (2004). Trapping and characterization of cold-responsive genes from T-DNA tagging lines in rice. Plant Sci. 166, 69-79. doi: 10.1016/j.plantsci.2003.08.008

Li, F., Guo, S., Zhao, Y., Chen, D., Chong, K., and Xu, Y. (2010). Overexpression of a homopeptide repeat-containing bHLH protein gene (OrbHLH001) from Dongxiang wild rice confers freezing and salt tolerance in transgenic Arabidopsis. Plant Cell Rep. 29, 977-986. doi: 10.1007/s00299-010-0883-z

Li, G., and Xue, H. W. (2007). Arabidopsis PLD zeta 2 regulates vesicle trafficking and is required for auxin response. Plant Cell 19, 281-295. doi: 10.1105/tpc.106. 041426

Li, P., Chen, F., Quan, C., and Zhang, G. Y. (2005). OsDREB1 gene from rice enhances cold tolerance in tobacco. Tsinghua Sci. Technol. 10, 478-483. doi: 10.1016/S1007-0214(05)70103-6

Liu, C., Wu, Y., and Wang, X. (2012). bZIP transcription factor OsbZIP52/RISBZ5 a potential negative regulator of cold and drought stress response in rice. Planta 235, 1157-1169. doi: 10.1007/s00425-011-1564-z

Liu, X., Bai, X., Wang, X., and Chu, C. (2007). OsWRKY71, a rice transcription factor, is involved in rice defense response. J. Plant Physiol. 164, 969-979. doi: 10.1016/j.jplph.2006.07.006

Liu, Y., Xu, Y., Xiao, J., Ma, Q., Li, D., Xue, Z., et al. (2011). OsDOG, a gibberellin-induced A20/AN1 zinc-finger protein, negatively regulates gibberellin-mediated cell elongation in rice. J. Plant Physiol. 168, 1098-1105. doi: 10.1016/j.jplph.2010.12.013

Lo, S. F., Yang, S. Y., Chen, K. T., Hsing, Y. I., Zeevaart, J. A., Chen, L. J., et al. (2008). A novel class of gibberellin 2-oxidases control semidwarfism, tillering, and root development in rice. Plant Cell 20, 2603-2618. doi: 10.1105/tpc.108.060913 
Marè, C., Mazzucotelli, E., Crosatti, C., Francia, E., Stanca, A., and Cattivelli, L. (2004). Hv-WRKY38: a new transcription factor involved in cold-and droughtresponse in barley. Plant Mol. Biol. 55, 399-416. doi: 10.1007/s11103-0040906-7

Mei, C., Qi, M., Sheng, G., and Yang, Y. (2006). Inducible overexpression of a rice allene oxide synthase gene increases the endogenous jasmonic acid level, PR gene expression, and host resistance to fungal infection. Mol. Plant Microbe Interact. 19, 1127-1137. doi: 10.1094/MPMI-19-1127

Miura, K., and Furumoto, T. (2013). Cold signaling and cold response in plants. Int. J. Mol. Sci. 14, 5312-5337. doi: 10.3390/ijms14035312

Miura, K., Jin, J. B., Lee, J., Yoo, C. Y., Stirm, V., Miura, T., et al. (2007). SIZ1mediated sumoylation of ICE1 controls CBF3/DREB1A expression and freezing tolerance in Arabidopsis. Plant Cell 19, 1403-1414. doi: 10.1105/tpc.106.048397

Mohanty, B., Krishnan, S. P., Swarup, S., Bajic, V. B. (2005). Detection and preliminary analysis of motifs in promoters of anaerobically induced genes of different plant species. Ann. Bot. 96, 669-681. doi: 10.1093/aob/mci219

Mohanty, J. G., Jaffe, J. S., Schulman, E. S., and Raible, D. G. (1997). A highly sensitive fluorescent micro-assay of $\mathrm{H} 2 \mathrm{O} 2$ release from activated human leukocytes using a dihydroxyphenoxazine derivative. J. Immunol. Methods 202, 133-141. doi: 10.1016/S0022-1759(96)00244-X

Mori, M., Nomura, T., Ooka, H., Ishizaka, M., Yokota, T., Sugimoto, K., et al. (2002). Isolation and characterization of a rice dwarf mutant with a defect in brassinosteroid biosynthesis. Plant Physiol. 130, 1152-1161. doi: 10.1104/pp. 007179

Murashige, T., and Skoog, F. (1962). A revised medium for rapid growth and bio assays with tobacco tissue cultures. Physiol. Plant. 15, 473-497. doi: 10.1111/j. 1399-3054.1962.tb08052.x

Ni, J., Wang, G., Zhu, Z., Zhang, H., Wu, Y., and Wu, P. (2011). OsIAA23-mediated auxin signaling defines postembryonic maintenance of QC in rice. Plant J. 68, 433-442. doi: 10.1111/j.1365-313X.2011.04698.x

Ogawa, M., Hanada, A., Yamauchi, Y., Kuwahara, A., Kamiya, Y., Yamaguchi, S. (2003). Gibberellin biosynthesis and response during Arabidopsis seed germination. Plant Cell 15, 1591-1604. doi: 10.1105/tpc.011650

Ono, A., Izawa, T., Chua, N. H., and Shimamoto, K. (1996). The rab16B promoter of rice contains two distinct abscisic acid-responsive elements. Plant Physiol. 112, 483-491. doi: 10.1104/pp.112.2.483

Piston, F., Uauy, C., Fu, L., Langston, J., Labavitch, J., and Dubcovsky, J. (2009). Down-regulation of four putative arabinoxylan feruloyl transferase genes from family PF02458 reduces ester-linked ferulate content in rice cell walls. Planta 231, 677-691. doi: 10.1007/s00425-009-1077-1

Qi, W., Sun, F., Wang, Q., Chen, M., Huang, Y., Feng, Y. Q., et al. (2011). Rice ethylene-response AP2/ERF factor OsEATB restricts internode elongation by down-regulating a gibberellin biosynthetic gene. Plant Physiol. 157, 216-228. doi: 10.1104/pp.111.179945

Qin, F., Sakuma, Y., Li, J., Liu, Q., Li, Y. Q., Shinozaki, K., et al. (2004). Cloning and functional analysis of a novel DREB1/CBF transcription factor involved in coldresponsive gene expression in Zea mays L. Plant Cell Physiol. 45, 1042-1052. doi: $10.1093 / \mathrm{pcp} / \mathrm{pch} 118$

Qiu, D., Xiao, J., Xie, W., Liu, H., Li, X., Xiong, L., et al. (2008). Rice gene network inferred from expression profiling of plants overexpressing OsWRKY13, a positive regulator of disease resistance. Mol. Plant 1, 538-551. doi: 10.1093/mp/ $\operatorname{ssn} 012$

Ren, D. Y., Rao, Y. C., Wu, L. W., Xun, Q. K., Li, Z. Z., Yu, H. P., et al. (2016). The pleiotropic ABNORMAL FLOWER AND DWARF1 affects plant height, floral development and grain yield in rice. J. Integr. Plant Biol. 58, 529-539. doi: $10.1111 /$ jipb.12441

Rerksiri, W., Zhang, X., Xiong, H., and Chen, X. (2013). Expression and promoter analysis of six heat stress-inducible genes in rice. Sci. World J. 2013, 397-401. doi: $10.1155 / 2013 / 397401$

Saijo, Y., Hata, S., Kyozuka, J., Shimamoto, K., and Izui, K. (2000). Over-expression of a single $\mathrm{Ca} 2+$-dependent protein kinase confers both cold and salt/drought tolerance on rice plants. Plant J. 23, 319-327. doi: 10.1046/j.1365-313x.2000. 00787.x

Sakuma, Y., Liu, Q., Dubouzet, J. G., Abe, H., Shinozaki, K., and YamaguchiShinozaki, K. (2002). DNA-binding specificity of the ERF/AP2 domain of Arabidopsis DREBs, transcription factors involved in dehydration- and coldinducible gene expression. Biochem. Biophys. Res. Commun. 290, 998-1009. doi: 10.1006/bbrc.2001.6299
Schmidt, R., Schippers, J. H., Mieulet, D., Obata, T., Fernie, A. R., Guiderdoni, E., et al. (2013). MULTIPASS, a rice R2R3-type MYB transcription factor, regulates adaptive growth by integrating multiple hormonal pathways. Plant J. 76, 258-273. doi: 10.1111/tpj.12286

Seo, J.-S., Joo, J., Kim, M.-J., Kim, Y.-K., Nahm, B. H., Song, S. I., et al. (2011). OsbHLH148, a basic helix-loop-helix protein, interacts with OsJAZ proteins in a jasmonate signaling pathway leading to drought tolerance in rice. Plant J. 65, 907-921. doi: 10.1111/j.1365-313X.2010.04477.x

Shakiba, E., Edwards, J. D., Jodari, F., Duke, S. E., Baldo, A. M., Korniliev, P., et al. (2017). Genetic architecture of cold tolerance in rice (Oryza sativa) determined through high resolution genome-wide analysis. PLoS ONE 12:e0172133. doi: 10.1371/journal.pone.0172133

Shan, X., Li, Y., Jiang, Y., Hao, W., and Yuan, Y. (2013). Transcriptome profile analysis of maize seedlings in response to high-salinity, drought and cold stresses by deep sequencing. Plant Mol. Biol. Rep. 31:1485. doi: 10.1007/s11105013-0622-Z

Shin, H., You, M. K., Jeung, J. U., and Shin, J. S. (2014). OsMPK3 is a TEY-type rice MAPK in Group C and phosphorylates OsbHLH65, a transcription factor binding to the E-box element. Plant Cell Rep. 33, 1343-1353. doi: 10.1007/ s00299-014-1620-9

Su, C. F., Wang, Y. C., Hsieh, T. H., Lu, C. A., Tseng, T. H., and Yu, S. M. (2010). A novel MYBS3-dependent pathway confers cold tolerance in rice. Plant Physiol. 153, 145-158. doi: 10.1104/pp.110.153015

Su, L., Li, J., Liu, D., Zhai, Y., Zhang, H., Li, X., et al. (2014). A novel MYB transcription factor, GmMYBj1, from soybean confers drought and cold tolerance in Arabidopsis thaliana. Gene 538, 46-55. doi: 10.1016/j.gene.2014. 01.024

Sun, S. J., Guo, S. Q., Yang, X., Bao, Y. M., Tang, H. J., Sun, H., et al. (2010). Functional analysis of a novel Cys2/His2-type zinc finger protein involved in salt tolerance in rice. J. Exp. Bot. 61, 2807-2818. doi: 10.1093/jxb/erq120

Sutoh, K., and Yamauchi, D. (2003). Two cis-acting elements necessary and sufficient for gibberellin-upregulated proteinase expression in rice seeds. Plant J. 34, 635-645. doi: 10.1046/j.1365-313X.2003.01753.x

Tang, M., Liu, X., Deng, H., and Shen, S. (2011). Over-expression of JcDREB, a putative AP2/EREBP domain-containing transcription factor gene in woody biodiesel plant Jatropha curcas, enhances salt and freezing tolerance in transgenic Arabidopsis thaliana. Plant Sci. 181, 623-631. doi: 10.1016/j.plantsci. 2011.06.014

Tao, Z., Kou, Y., Liu, H., Li, X., Xiao, J., and Wang, S. (2011). OsWRKY45 alleles play different roles in abscisic acid signalling and salt stress tolerance but similar roles in drought and cold tolerance in rice. J. Exp. Bot. 62, 4863-4874. doi: $10.1093 /$ jxb/err144

Terada, R., Nakayama, T., Iwabuchi, M., and Shimamoto, K. (1993). A wheat histone $\mathrm{H} 3$ promoter confers cell division-dependent and -independent expression of the gus A gene in transgenic rice plants. Plant J. 3, 241-252.

Tsutsui, T., Kato, W., Asada, Y., Sako, K., Sato, T., Sonoda, Y., et al. (2009). DEAR1, a transcriptional repressor of DREB protein that mediates plant defense and freezing stress responses in Arabidopsis. J. Plant Res. 122, 633. doi: 10.1007/ s10265-009-0252-6

Ueguchi-Tanaka, M., Ashikar, M., Nakajima, M., Itoh, H., Katoh, E., Kobayashi, M., et al. (2005). GIBBERELLIN INSENSITIVE DWARF1 encodes a soluble receptor for gibberellin. Nature 437, 693-698. doi: 10.1038/nature04028

Urbanczyk-Wochniak, E., Usadel, B., Thimm, O., Nunes-Nesi, A., Carrari, F., Davy, M., et al. (2006). Conversion of MapMan to allow the analysis of transcript data from Solanaceous species: effects of genetic and environmental alterations in energy metabolism in the leaf. Plant Mol. Biol. 60, 773-792. doi: 10.1007/s11103-005-5772-4

Usadel, B., Blasing, O. E., Gibon, Y., Retzlaff, K., Hoehne, M., Gunther, M., et al. (2008). Multilevel genomic analysis of the response of transcripts, enzyme activities and metabolites in Arabidopsis rosettes to a progressive decrease of temperature in the non-freezing range. Plant Cell Environ. 31, 518-547. doi: 10.1111/j.1365-3040.2007.01763.x

Usadel, B., Nagel, A., Thimm, O., Redestig, H., Blaesing, O. E., Palacios-Rojas, N., et al. (2005). Extension of the visualization tool MapMan to allow statistical analysis of arrays, display of corresponding genes, and comparison with known responses. Plant Physiol. 138, 1195-1204. doi: 10.1104/pp.105.060459

Vannini, C., Locatelli, F., Bracale, M., Magnani, E., Marsoni, M., Osnato, M., et al. (2004). Overexpression of the rice Osmyb4 gene increases chilling and freezing 
tolerance of Arabidopsis thaliana plants. Plant J. 37, 115-127. doi: 10.1046/j. 1365-313X.2003.01938.x

Verma, V., Ravindran, P., and Kumar, P. P. (2016). Plant hormone-mediated regulation of stress responses. BMC Plant Biol. 16:86. doi: 10.1186/s12870-0160771-y

Wan, L., Zhang, J., Zhang, H., Zhang, Z., Quan, R., Zhou, S., et al. (2011). Transcriptional activation of OsDERF1 in OsERF3 and OsAP2-39 negatively modulates ethylene synthesis and drought tolerance in rice. PLOS ONE 6:e25216. doi: 10.1371/journal.pone.0025216

Wang, C., Wei, Q., Zhang, K., Wang, L., Liu, F., Zhao, L., et al. (2013). Downregulation of OsSPX1 causes high sensitivity to cold and oxidative stresses in rice seedlings. PLOS ONE 8:e81849. doi: 10.1371/journal.pone.0081849

Wang, D., Liu, J., Li, C., Kang, H., Wang, Y., Tan, X., et al. (2016). Genome-wide association mapping of cold tolerance genes at the seedling stage in rice. Rice 9:61. doi: 10.1186/s12284-016-0133-2

Wang, F., Hou, X., Tang, J., Wang, Z., Wang, S., Jiang, F., et al. (2012). A novel coldinducible gene from Pak-choi (Brassica campestris ssp. chinensis), BcWRKY46, enhances the cold, salt and dehydration stress tolerance in transgenic tobacco. Mol. Biol. Rep. 39, 4553-4564. doi: 10.1007/s11033-011-1245-9

Wang, J., Ding, H., Zhang, A., Ma, F., Cao, J., and Jiang, M. (2010). A novel mitogen-activated protein kinase gene in maize (Zea mays), ZmMPK3, is involved in response to diverse environmental cues. J. Integr. Plant Biol. 52, 442-452. doi: 10.1111/j.1744-7909.2010.00906.x

Wang, X., Li, W., Li, M., and Welti, R. (2006). Profiling lipid changes in plant response to low temperatures. Physiol. Plant. 126, 90-96. doi: 10.1111/j.13993054.2006.00622.x

Wang, X. C., Zhao, Q. Y., Ma, C. L., Zhang, Z. H., Cao, H. L., Kong, Y. M., et al. (2013). Global transcriptome profiles of Camellia sinensis during cold acclimation. BMC Genomics 14:415. doi: 10.1186/1471-2164$14-415$

Wang, Y., and He, C. (2007). Isolation and characterization of a cold-induced DREB gene from Aloe vera L. Plant Mol. Biol. Report. 25, 121-132. doi: 10.1007/ s11105-007-0014-3

Wang, Y., Shu, Z., Wang, W. X., Jiang, D., Li, J., Pan, X., et al. (2016). CsWRKY2, a novel WRKY gene from Camellia sinensis, is involved in cold and drought stress responses. Biol. Plant. 60, 443. doi: 10.1007/s10535-016-0618-2

Wang, Y. J., Zhang, Z. G., He, X. J., Zhou, H. L., Wen, Y. X., Dai, J. X., et al. (2003). A rice transcription factor OsbHLH1 is involved in cold stress response. Theor Appl. Genet. 107, 1402-1409. doi: 10.1007/s00122-003-1378-x

Wang, Z., Ruan, W., Shi, J., Zhang, L., Xiang, D., Yang, C., et al. (2014). Rice SPX1 and SPX2 inhibit phosphate starvation responses through interacting with PHR2 in a phosphate-dependent manner. Proc. Natl. Acad. Sci. U.S.A. 111, 14953-14958. doi: 10.1073/pnas.1404680111

Wei, J., Wu, Y., Cho, L. H., Yoon, J., Choi, H., Yoon, H., et al. (2017). Identification of root-preferential transcription factors in rice by analyzing GUS expression patterns of T-DNA tagging lines. J. Plant Biol. 60, 268-277. doi: 10.1007/s12374016-0597-Z

Wei, S., Du, Z., Gao, F., Ke, X., Li, J., Liu, J., et al. (2015). Global transcriptome profiles of 'Meyer' zoysiagrass in response to cold stress. PLoS ONE 10:e0131153. doi: 10.1371/journal.pone.0131153

Wu, L., Chen, X., Ren, H., Zhang, Z., Zhang, H., Wang, J., et al. (2007). ERF protein JERF1 that transcriptionally modulates the expression of abscisic acid biosynthesis-related gene enhances the tolerance under salinity and cold in tobacco. Planta 226, 815-825. doi: 10.1007/s00425-007-0528-9

Wuriyanghan, H., Zhang, B., Cao, W. H., Ma, B., Lei, G., Liu, Y. F., et al. (2009). The ethylene receptor ETR2 delays floral transition and affects starch accumulations in rice. Plant Cell 21, 1473-1494. doi: 10.1105/tpc.108.065391

Xiang, D., Man, L., Yin, K., Song, Q., Wang, L., Zhao, M., et al. (2013). Overexpression of a ItICE1 gene from Isatis tinctoria enhances cold tolerance in rice. Mol. Breed. 32, 617-628. doi: 10.1007/s11032-013-9894-0

Xiong, A. S., Jiang, H. H., Zhuang, J., Peng, R. H., Jin, X. F., Zhu, B., et al. (2013). Expression and function of a modified AP2/ERF transcription factor from Brassica napus enhances cold tolerance in transgenic Arabidopsis. Mol. Biotechnol. 53, 198-206. doi: 10.1007/s12033-012-9515-x

Xiong, L., and Yang, Y. (2003). Disease resistance and abiotic stress tolerance in rice are inversely modulated by an abscisic acid-inducible mitogen-activated protein kinase. Plant Cell 15, 745-759. doi: 10.1105/tpc.008714
Xu, W., Zhang, N., Jiao, Y., Li, R., Xiao, D., and Wang, Z. (2014). The grapevine basic helix-loop-helix (bHLH) transcription factor positively modulates CBFpathway and confers tolerance to cold-stress in Arabidopsis. Mol. Biol. Rep. 41, 5329-5342. doi: 10.1007/s11033-014-3404-2

Yaish, M. W., El-Kereamy, A., Zhu, T., Beatty, P. H., Good, A. G., Bi, Y. M., et al. (2010). The APETALA-2-like transcription factor OsAP2-39 controls key interactions between abscisic acid and gibberellin in rice. PLoS Genet. 6:e1001098. doi: 10.1371/journal.pgen.1001098

Yamaguchi, T., Kuroda, M., Yamakawa, H., Ashizawa, T., Hirayae, K., Kurimoto, L., et al. (2009). Suppression of a phospholipase D gene, OsPLD beta 1, activates defense responses and increases disease resistance in rice. Plant Physiol. 150, 308-319. doi: 10.1104/pp.108.131979

Yamamoto, E., Yonemaru, J.-I., Yamamoto, T., and Yano, M. (2012). OGRO: the overview of functionally characterized Genes in Rice online database. Rice 5, 1-10. doi: 10.1186/1939-8433-5-26

Yan, Y. S., Chen, X. Y., Yang, K., Sun, Z. X., Fu, Y. P., Zhang, Y. M., et al. (2011). Overexpression of an F-box protein gene reduces abiotic stress tolerance and promotes root growth in rice. Mol. Plant 4, 190-197. doi: 10.1093/mp/ ssq066

Yang, A., Dai, X. Y., and Zhang, W. H. (2012). A R2R3-type MYB gene, OsMYB2, is involved in salt, cold, and dehydration tolerance in rice. J. Exp. Bot. 63, 2541-2556. doi: 10.1093/jxb/err431

Yang, Y., Chen, H., Jen, W., Liu, L., and Chang, M. (2015). Comparative transcriptome analysis of shoots and roots of TNG67 and TCN1 rice seedlings under cold stress and following subsequent recovery: insights into metabolic pathways, phytohormones, and transcription Factors. PLoS ONE 10:e0131391. doi: 10.1371/journal.pone. 0131391

Yokotani, N., Sato, Y., Tanabe, S., Chujo, T., Shimizu, T., Okada, K., et al. (2013). OsWRKY76 is a rice transcriptional repressor playing opposite roles in blast disease resistance and cold stress tolerance. J. Exp. Bot. 64, 5085-5097. doi: $10.1093 / \mathrm{jxb} / \mathrm{ert} 298$

You, J., Zong, W., Li, X., Ning, J., Hu, H., Li, X., et al. (2013). The SNAC1-targeted gene OsSRO1c modulates stomatal closure and oxidative stress tolerance by regulating hydrogen peroxide in rice. J. Exp. Bot. 64, 569-583. doi: 10.1093/ jxb/ers349

Zhai, H., Bai, X., Zhu, Y., Li, Y., Cai, H., Ji, W., et al. (2010). A single-repeat R3MYB transcription factor MYBC1 negatively regulates freezing tolerance in Arabidopsis. Biochem. Biophys. Res. Commun. 394, 1018-1023. doi: 10.1016/j. bbrc.2010.03.114

Zhang, F., Huang, L., Wang, W., Zhao, X., Zhu, L., Fu, B., et al. (2012). Genomewide gene expression profiling of introgressed indica rice alleles associated with seedling cold tolerance improvement in a japonica rice background. $B M C$ Genomics 7:461. doi: 10.1186/1471-2164-13-461

Zhang, H., Ni, L., Liu, Y., Wang, Y., Zhang, A., Tan, M., et al. (2012). The C2H2type zinc finger protein ZFP182 is involved in abscisic acid-induced antioxidant defense in rice. J. Integr. Plant Biol. 54, 500-510. doi: 10.1111/j.1744-7909.2012. 01135.x

Zhang, Q., Chen, Q. H., Wang, S. L., Hong, Y. H., and Wang, Z. L. (2014). Rice and cold stress: methods for its evaluation and summary of cold tolerance-related quantitative trait loci. Rice 7, 24-35. doi: 10.1186/s12284-014-0024-3

Zhang, T., Zhao, X., Wang, W., Pan, Y., Huang, L., Liu, X., et al. (2012). Comparative transcriptome profiling of chilling stress responsiveness in two contrasting rice genotypes. PLOS ONE 7:e43274. doi: 10.1371/journal.pone. 0043274

Zhang, Y., Chen, C., Jin, X. F., Xiong, A. S., Peng, R. H., Hong, Y. H., et al. (2009). Expression of a rice DREB1 gene, OsDREB1D, enhances cold and highsalt tolerance in transgenic Arabidopsis. BMB Rep. 42, 486-492. doi: 10.5483/ BMBRep.2009.42.8.486

Zhang, Y., Yu, H., Yang, X., Li, Q., Ling, J., Wang, H., et al. (2016). CsWRKY46, a WRKY transcription factor from cucumber, confers cold resistance in transgenic-plant by regulating a set of cold-stress responsive genes in an ABAdependent manner. Plant Physiol. Biochem. 108, 478-487. doi: 10.1016/j.plaphy. 2016.08.013

Zhao, C., Xu, J., Chen, Y., Mao, C., Zhang, S., Bai, Y., et al. (2012). Molecular cloning and characterization of OsCHR4, a rice chromatin-remodeling factor required for early chloroplast development in adaxial mesophyll. Planta 236, 1165-1176. doi: 10.1007/s00425-012-1667-1 
Zhao, J., Zhang, S., Yang, T., Zeng, Z., Huang, Z., Liu, Q., et al. (2014). Global transcriptional profiling of a cold-tolerant rice variety under moderate cold stress reveals different cold stress response mechanisms. Physiol. Plant. 154, 381-394. doi: 10.1111/ppl.12291

Zheng, X., Chen, B., Lu, G., and Han, B. (2009). Overexpression of a NAC transcription factor enhances rice drought and salt tolerance. Biochem. Biophys. Res. Commun. 379, 985-989. doi: 10.1016/j.bbrc.2008.12.163

Zhi-guo, E., Wang, L., Qin, R., Shen, H., and Zhou, J. (2014). Genome-wide characterisation of gene expression in rice leaf blades at $25^{\circ} \mathrm{C}$ and $30^{\circ} \mathrm{C}$. Sci. World J. 7, 917292. doi: 10.1155/2014/917292

Zhou, G., Qi, J., Ren, N., Cheng, J., Erb, M., Mao, B., et al. (2009). Silencing OsHI-LOX makes rice more susceptible to chewing herbivores, but enhances resistance to a phloem feeder. Plant J. 60, 638-648. doi: 10.1111/j.1365-313X. 2009.03988.x

Zhu, J., Verslues, P. E., Zheng, X., Lee, B. H., Zhan, X., Manabe, Y., et al. (2005). HOS10 encodes an R2R3-type MYB transcription factor essential for cold acclimation in plants. Proc. Natl. Acad. Sci. U.S.A. 102, 9966-9971. doi: 10.1073/ pnas.0503960102

Zou, C. S., Jiang, W. B., and Yu, D. Q. (2010). Male gametophyte-specific WRKY34 transcription factor negatively mediates cold stress tolerance of mature pollen in Arabidopsis. J. Exp. Bot. 61, 3901-3914. doi: 10.1093/jxb/erq204

Conflict of Interest Statement: The authors declare that the research was conducted in the absence of any commercial or financial relationships that could be construed as a potential conflict of interest.

Copyright (C) 2017 Kumar, Gho, Jung and Kim. This is an open-access article distributed under the terms of the Creative Commons Attribution License (CC BY). The use, distribution or reproduction in other forums is permitted, provided the original author(s) or licensor are credited and that the original publication in this journal is cited, in accordance with accepted academic practice. No use, distribution or reproduction is permitted which does not comply with these terms. 